\title{
A CRITERION FOR BRITTLE FAILURE OF ROCKS USING THE THEORY OF CRITICAL DISTANCES
}

\author{
by \\ Jorge Castro $\left({ }^{1}\right)(*)$, Sergio Cicero $\left({ }^{2}\right)$ and César Sagaseta $\left({ }^{3}\right)$ \\ Department of Ground Engineering and Materials Science \\ University of Cantabria \\ Avda. de Los Castros, s/n \\ 39005 Santander, Spain \\ Tel.: +34 942201813 \\ Fax: +34 942201821 \\ e-mail: $\left({ }^{1}\right)$ castrogj@unican.es $\left({ }^{2}\right)$ ciceros@unican.es $\left({ }^{3}\right)$ sagasetac@unican.es \\ (*) Corresponding Author
}

Date: February 2015

Number of words: 6,100

Number of tables: 2

Number of figures: 18 


\section{ABSTRACT}

This paper presents a new analytical criterion for brittle failure of rocks and heavily overconsolidated soils. Griffith's model of a randomly oriented defect under a biaxial stress state is used to keep the criterion simple. The Griffith's criterion is improved because the maximum tensile strength is not evaluated at the boundary of the defect but at a certain distance from the boundary, known as the critical distance. This fracture criterion is known as the Point Method, and is part of the Theory of Critical Distances, which is utilized in fracture mechanics. The proposed failure criterion has two parameters: the inherent tensile strength, $\sigma 0$, and the ratio of the half-length of the initial crack/flaw to the critical distance, $a / L$. These parameters are difficult to measure but they may be correlated with the uniaxial compressive and tensile strengths, $\sigma_{c}$ and $\sigma_{t}$. The proposed criterion is able to reproduce the common range of strength ratios for rocks and heavily overconsolidated soils $\left(\sigma_{c} / \sigma_{t}=3-50\right)$ and the influence of several microstructural rock properties, such as texture and porosity. Good agreement with laboratory tests reported in the literature is found for tensile and low confining stresses.

KEYWORDS: Brittle failure; crack; critical distance; failure criterion; rock strength. 


\section{NOTATION}

\begin{tabular}{|c|c|}
\hline$a, b$ & Major and minor semi-axes of an elliptical flaw \\
\hline$a$ & Half-length of a crack \\
\hline$m$ & Ratio of minor to major axis of an elliptical flaw \\
\hline$m_{i}$ & Parameter of the Hoek-Brown criterion \\
\hline$n$ & Porosity \\
\hline $\mathrm{r}$ & Pearson's correlation coefficient \\
\hline$t$ & Time \\
\hline$w$ & Moisture content \\
\hline$G$ & Grain size \\
\hline$L$ & Critical distance \\
\hline$\beta$ & Angle between the direction of the major principal stress and $x$-axis \\
\hline$\sigma$ & Normal stress \\
\hline$\sigma_{t}$ & Uniaxial tensile strength \\
\hline$\sigma_{c}$ & Unconfined compressive strength \\
\hline$\sigma_{0}$ & Inherent tensile stress \\
\hline$\tau$ & Shear stress \\
\hline
\end{tabular}

Subscripts:

$\operatorname{avg}$

Average

$\max$

Maximum

1,3 Major and minor principal stresses

$x, y \quad$ Cartesian coordinates 
Polar coordinates

Sign convention:

Compressive stresses are assumed as positive throughout the paper. 


\section{INTRODUCTION}

The development of failure criteria is of primary importance in engineering practice. They are used as simple rules to predict failure in brittle materials or yielding in ductile materials. Rocks behave as ductile materials at high confining compressive stresses, while at low confining stresses or under tension, they show brittle failure. The propagation of cracks, which act as stress risers in the material, leads to rock's brittle behaviour. Crack propagation and damage are studied by the theory of fracture mechanics, which was initiated by Griffith $(1921$; 1924), focusing on brittle failure of glass. His work also included the development of a failure criterion, which will be explained in detail in the next section.

The application of fracture mechanics to rocks historically evolved with that of the practice of rock mechanics and the ground control challenges arising from deep mining in South Africa. This required the detailed study of brittle rock failure together with the development of indirect tests to measure tensile strength and triaxial cells for systematic rock testing (Hoek 1965; Bieniawski 1967; Jaeger 1967). Since then, fracture mechanics and its application to rocks has progressed with focus on: different types of cracks (Bobet 2000), mixed modes of fracture (Shen and Stephansson 1993), fluid pressure, rock anisotropy, three-dimensional effects, friction between the lips of the crack, crack density, crack propagation (Kemeny 1991) and crack coalescence (Bobet 1998). Intact rocks share many common features with unreinforced concrete and, therefore, advances in the modelling of concrete fracturing (e.g. Karihaloo et al. 1993; Elices et al. 2000; Bažant 2002) are also relevant. In recent years, numerical approaches (e.g. Ingraffea and 
Heuzé 1980; Wu and Wong 2012) have benefited from the increase in computing power. Despite this body of research, the most popular failure criterion for rocks is probably the Hoek-Brown shear criterion (Hoek and Brown 1980), which is based on empirical fitting of triaxial test results using an algebraic expression related to Griffith's formulation (Hoek 1968), as commented in Section 2 below. The Mohr-Coulomb shear failure criterion, which employs cohesive and frictional strength components, and a tension cut-off to model the proper uniaxial tensile strength, is another simple alternative. There are some other empirical criteria, such as Johnston (1985), with higher degrees of freedom, i.e. more fitting parameters, and consequently, better agreement but higher uncertainty in the selection of the fitting parameters. Empirical criteria are generally used to study shear failure but they may also consider lower confining stresses, including brittle failure. Therefore, in the case of non-linear criteria, their curvature is partly caused by the brittle-ductile transition of the material under high confinement (Paterson and Wong 2005).

Following the general idea of the Griffith's criterion, some authors have also proposed advanced micromechanical models (e.g. Baud et al. 2014). The analysis of rock behaviour at the microscale level helps to understand and explain phenomena at the macroscopic level. One of the most powerful and recent advances in fracture mechanics is the development of the Theory of Critical Distances, or TCD (Taylor 2007). This theory allows an analysis of crack initiation using just stress fields, which is more convenient in rock mechanics than using energy dissipation concepts or stress intensity factors. A brief review of this theory is presented in Section 3. 
In this paper, the theory of critical distances and a micromechanical model similar to that of Griffith are used to develop a simple failure criterion for brittle failure of rocks under a low confinement biaxial stress state. This model, despite its simplifying hypotheses, is theoretically based, uses rock parameters with physical meaning, and captures quite well the ratio between unconfined compressive strength and uniaxial tensile stress $\left(\sigma_{c} / \sigma_{t}\right)$ observed in brittle rock failure.

\section{GRIFFITH'S CRITERION}

Griffith $(1921 ; 1924)$ used thermodynamic concepts to study the growth of a thin crack due to an applied load. A key aspect of his analysis is that some energy is dissipated through the development of new crack faces as a crack grows. However, the so-called Griffith's criterion for brittle failure does not use those thermodynamic concepts and is purely based on stresses, i.e. the stress field around an elliptical defect or flaw and the maximum tensile stress at the defect boundary that is necessary for crack initiation. Jaeger et al. (2007) clearly explained that, although both approaches are due to Griffith, they are fundamentally different, as the failure criterion assumes a "critical stress" at the defect boundary for crack initiation, rather than a criterion based on energy release.

Griffith (1924) used the conceptual model of a material containing a randomly oriented thin elliptical flaw (Figure 1). This model simplifies the problem to two dimensions, neglects the interaction between adjacent flaws, and assumes a homogenous elastic material. It can be shown that very high tensile stresses occur at the boundary of a

suitably oriented thin ellipse, even under compressive stress conditions (e.g. Maugis 
1992). The selection of an elliptical flaw by Griffith was done to avoid the singularity in $1 / \sqrt{ } r$ of the stresses at the tip of an infinitely sharp crack (Sneddon 1946).

The development of the Griffith's criterion slightly varies depending on the mathematical treatment of the stresses around the ellipse. For example, Hoek (1968) follows the original approach and presents the maximum tensile stress as a function of the normal and shear stresses. A summary of the derivation is given below. Hoek (1968) uses the local axes of the ellipse (where the $x$ axis is aligned with the major axis; see Figure 1):

$$
\begin{aligned}
& 2 \sigma_{x}=\left(\sigma_{1}+\sigma_{3}\right)+\left(\sigma_{1}-\sigma_{3}\right) \cos (2 \beta) \\
& 2 \sigma_{y}=\left(\sigma_{1}+\sigma_{3}\right)-\left(\sigma_{1}-\sigma_{3}\right) \cos (2 \beta) \\
& 2 \tau_{x y}=\left(\sigma_{1}-\sigma_{3}\right) \sin (2 \beta)
\end{aligned}
$$

Using the solution developed by Inglis (1913) for the stresses at the boundary of an elliptical flaw, assuming that it is very flat, i.e. a very small ratio of the minor to major axes of the ellipse $b / a=m$, and neglecting terms of minor importance, the tangential or hoop stress at the boundary of the elliptical flaw and near its tip is given by the following approximate expression:

$$
\sigma_{\theta}=\frac{2\left(m \sigma_{y}-\alpha \tau_{x y}\right)}{m^{2}+\alpha^{2}}
$$

where $\alpha$ is the eccentric angle, which is related to the global polar angle, $\theta^{\prime}$ :

$$
\tan \alpha=\tan \theta^{\prime} / m
$$

Note that both a global polar coordinate system, centred at the centre of the elliptical cavity $\left(r^{\prime}, \theta^{\prime}\right)$, and a local polar coordinate system, centred at the focal point of the ellipse $(r, \theta)$, are used (Figure 2). 
The value of $\alpha$, i.e. the coordinate of the point at the cavity boundary and near the tip, that gives the maximum tensile stress is substituted in Eq. (2):

$$
m \sigma_{\theta, \max }=\sigma_{y} \pm \sqrt{\sigma_{y}^{2}+\tau_{x y}^{2}}
$$

Griffith's criterion assumes that a crack will initiate from the boundary of the elliptical flaw when the maximum tensile stress at the boundary $\left(\sigma_{\theta, \max }\right.$, Eq. 4$)$ reaches a limiting value, which is usually referred to as the local tensile strength of the material surrounding the elliptical flaw. Furthermore, this crack initiation is identified with "failure" of the rock. To avoid using the local tensile strength and the axis ratio, $m$, they are related to the uniaxial tensile strength, $\sigma$ t, applying Eq. (4) to the case of uniaxial tension $\left(\sigma_{y}=\sigma_{t}\right.$ and $\left.\tau_{x y}=0\right)$ :

$$
m \sigma_{\theta, \max }=2 \sigma_{t}
$$

Substituting Eq. (5) into Eq. (4), the equation of the Griffith's criterion in the Mohr's diagram is obtained:

$$
\tau_{x y}^{2}=4 \sigma_{t}\left(\sigma_{t}-\sigma_{y}\right)
$$

Note that, in substituting a numerical value of the uniaxial tensile strength, $\sigma$, a negative sign has to be included in order to satisfy the sign convention adopted in this paper (compressive stresses are positive).

The Griffith's criterion may also be expressed in terms of principal stresses:

$$
\begin{array}{ll}
\text { If } \quad \sigma_{1} \leq-3 \sigma_{t}, & \sigma_{3}=\sigma_{t} \\
\text { If } \quad \sigma_{1} \geq-3 \sigma_{t}, & \left(\sigma_{1}-\sigma_{3}\right)^{2}=-8 \sigma_{t}\left(\sigma_{1}+\sigma_{3}\right)
\end{array}
$$


The criterion for crack initiation used in the Griffith's model has been referred to as the Maximum Tangential Stress (MTS) criterion and has been used to determine the direction of crack propagation (Erdogan and Sih 1963). Nevertheless, it has long been recognised that this criterion requires another length constant to be strictly valid and to account for "size effects" (e.g. Williams and Ewing 1972; Lajtai 1972; Chang 1981); i.e. the influence of the absolute size of the defect or elliptical flaw usually called the critical distance. In the following, the theory of critical distances is briefly presented to provide the theoretical background of an applicable criterion for fracture initiation based on the stress field around a defect.

\section{THEORY OF CRITICAL DISTANCES}

In fracture mechanics, failure criteria may be considered as global or local fracture criteria (Bao and Jin 1993; Pluvinage 1998). The common example of global criteria is that used by linear-elastic fracture mechanics (LEFM) for the analysis of cracks, where failure occurs when the stress intensity factor reaches a critical value, known as fracture toughness:

$$
K_{I}=K_{I C}
$$

On the contrary, local criteria use the stress value of a single point, line, area or volume close to the crack tip, but they do not globally consider the stress field through, for example, $K_{I}$. Among local criteria, those criteria belonging to the Theory of Critical Distances (TCD) stand out. The TCD is essentially a group of methodologies, all of which use a characteristic material length parameter (the critical distance, $L$ ) when performing fracture assessments (Taylor 2007). The origins of the TCD date back to the middle of the twentieth century with the works of Neuber (1958) and Peterson (1959), 
but it has been in the last years, driven by the proliferation of finite element stress analyses, that this theory has been scientifically analysed and applied to: different types of materials (metals, ceramics, polymers and composites); failure or damage processes (fracture and fatigue); and conditions (linear-elastic vs. elastoplastic). Examples include Taylor (2007), Cicero et al. (2012; 2013), Madrazo et al. (2012), Susmel and Taylor (2010), and Taylor and Wang (2000). Recently, the authors have successfully applied the TCD to two rock types, namely limestone and granite (Cicero et al. 2014).

The critical distance may be obtained through the following expression:

$$
L=\frac{1}{\pi}\left(\frac{K_{I C}}{\sigma_{0}}\right)^{2}
$$

where $K_{I C}$ is the material fracture toughness and $\sigma_{0}$ is a characteristic material strength parameter named the inherent strength, usually larger than the ultimate tensile strength $\left(\sigma_{t}\right)$, which requires calibration.

Among the different methodologies included within the TCD, two of them are particularly simple to apply: the Point Method (PM), also known as the Stress Method, and the Line Method (LM). Both of these are based on the stress field at the defect tip. Other methodologies, such as Finite Fracture Mechanics (FFM) and the Imaginary Crack Method are based on the stress intensity factor and their application is not so straightforward. In any case, as stated by Taylor (2007), the predictions made by all these methodologies are very similar, so that only the PM and the LM, those with a far simpler application, will be considered here. 
The Point Method (PM) is the simplest methodology and it assumes that fracture occurs when the stress reaches the inherent strength $\left(\sigma_{0}\right)$ at a certain distance $\left(r_{\mathrm{c}}\right)$ from the crack tip. Assuming linear-elastic behaviour, then based on the stress field at the crack tip at failure (Taylor 2007; Anderson 2004) and the definition of $L$ (Eq. (9)), it is straightforward to demonstrate that $r_{\mathrm{c}}$ equals $L / 2$ :

$$
\frac{K_{I C}}{\sqrt{2 \pi r_{c}}}=\sigma_{0} \Rightarrow r_{c}=\frac{1}{2 \pi}\left(\frac{K_{I C}}{\sigma_{0}}\right)^{2}=\frac{L}{2}
$$

The PM failure criterion is therefore:

$$
\sigma_{\theta}\left(r=\frac{L}{2} ; \theta=0\right)=\sigma_{0}
$$

For comparison, the Line Method (LM) assumes that fracture occurs when the average stress along a line extending a certain distance, $d$, from the crack tip reaches the inherent strength, $\sigma_{0}$. Again, from the stress field at the crack tip at failure and the definition of $L$, it is easy to demonstrate that $d$ is equal to $2 L$ :

$$
\frac{1}{d} \int_{0}^{d} \frac{K_{I C}}{\sqrt{2 \pi r}} d r=\frac{2}{\sqrt{2 \pi}} \frac{K_{I C}}{d^{1 / 2}}=\sigma_{0} \Rightarrow d=\frac{4}{2 \pi}\left(\frac{K_{I C}}{\sigma_{0}}\right)^{2}=2 L
$$

Therefore, the LM failure criterion is:

$$
\frac{1}{2 L} \int_{0}^{2 L} \sigma_{\theta}(r) d r=\sigma_{0}
$$

The TCD, applying the PM and the LM, allows the fracture assessment of components with any kind of stress riser to be performed. As an example, when using the PM it would be sufficient to perform two fracture tests on two specimens with different types of defects (e.g. sharp notch and blunt notch). The corresponding stress-distance 
curves at fracture, which can be determined by using analytical solutions or finite element methods, cross each other at a point with coordinates $\left(L / 2, \sigma_{0}\right)$, as shown in Figure 3. The prediction of the fracture load of any other component made of the same material and containing any other kind of defect would require the definition of the corresponding stress field, the fracture load being that one for which Eq. (11) is fulfilled. In some cases with linear-elastic behaviour at both the micro and the macro scales, $\sigma_{0}$ coincides with $\sigma_{t}$ and the application of the TCD is even simpler, given that there is no need to calibrate $\sigma_{0}$ and $L$ (directly provided by Eq. (9) once both $K_{I C}$ and $\sigma_{t}$ are known).

Despite the potential of the TCD for the analysis of fracture processes, to date the application of this theory to rocks has been limited. To the knowledge of the authors, Lajtai (1972) was the first author to apply the PM to rocks. He successfully reproduced rock fracture around a circular defect using the stress gradient at the defect boundary to calculate the stress at the critical distance. Lajtai (1972) considered the PM as an approach that accounts for the stress redistribution across a process zone ahead of the crack tip. Another successful application of the PM has been done by Ito and Hayashi (1991) and Ito (2008) to study hydraulic fracturing from a wellbore. These applications involve Mode I fracturing (tension), where the crack propagates along its plane following a straight path; the TCD was originally developed for Mode I fracturing (Taylor 2007).

In rocks, compressive and shear stresses are common and lead to mixed modes of fracture. However, crack initiation is always caused by tensile stresses and crack 
propagation follows a pure Mode I fracturing path (Cotterell 1965; Cotterell and Rice 1980). Based on this, the PM has been successfully applied to mixed mode fracturing (Williams and Ewing 1972; Smith et al. 2001), assuming that the maximum tangential stress is reached along the fracturing path, which forms an angle $\theta_{0}$ with the flaw plane. The application of the PM to mixed modes of fracture is illustrated in Figure 4. The method is equivalent to that used in pure mode I (Eq. 10), but now, the direction of the maximum tangential stress, $\theta_{0}$, has to be found. Smith et al. (2001) called the method the Generalised Maximum Tangential Stress (GMTS) criterion as an extension of the MTS criterion (Erdogan and Sih 1963). Recently, the authors of the GMTS and their coworkers have extensively applied the method to different materials, including Harsin marble (Aliha et al. 2012) and Guiting limestone (Aliha et al. 2010). It is worth noting that these authors always assume that the inherent tensile strength $\left(\sigma_{0}\right)$ coincides with $\sigma_{t}$ and in this paper it will be assumed, as shown later, that the tensile strength at the macro scale $\left(\sigma_{t}\right)$ is lower than the inherent tensile strength (at the micro scale) because $\sigma_{t}$ is influenced by the small-scale flaws and microfractures present in the intact rock.

The physical meaning of $L$ and $\sigma_{0}$ is not fully clear, but it should be somehow related with the material microstructure (Figure 5). The high tensile stresses near the defect tip predicted by the mathematical theory of elasticity, which assumes a perfectly homogenous material, are not realistic. What is more probable is that those stresses are redistributed over an area near the defect tip; several authors (e.g. Dyskin 1997; Zhou and Gou 2009) refer to this area as the fracture process zone (FPZ). The redistribution of stresses near the defect tip may be related to local plasticity and/or microstructural features, such as the grain size. So, some proportionality between the critical distance 
and the grain size is expected. Moreover, Figure 6 presents the physical observation on which the TCD is based: crack propagation is more of an intermittent process than a continuous phenomenon. That is, it takes place through small crack size increments whose length is, precisely, two times the critical distance $(2 L)$ and constitutes a material parameter. This is the basis of Finite Fracture Mechanics (FFM), the methodology belonging to the TCD that provides a more satisfactory physical (mechanistic) explanation of the fracture process. Details on this may be found in Taylor (2007).

Taylor (2007) also presents a summary of works that have analysed the physical meaning of the critical distance. The first comment on this is that, depending on the material being analysed, $L$ may take values that range from the atomic separation (Pugno and Ruoff 2004) up to meters (Dempsey et al. 1999) for certain specific situations such as nanomaterials and sea ice, respectively, with typical values from tens of microns up to a number of centimetres. Taylor (2007) distinguishes here two situations when trying to relate the critical distance to the material characteristics: small values of $L$ (e.g. ceramics and steels) are simply related to the microstructure, especially to the grain size $(D)$, which acts as a barrier to crack propagation and thus generates the above mentioned discontinuous crack growth; large values of $L$ are associated with a damage zone (e.g. composites and certain polymers).

Concerning the published relations between the critical distance and the microstructure, Usami et al. (1986) provided relations on which the critical distance ranges between one and ten times the grain size $(D)$ in ceramics. The values of $L$ in rocks obtained in (Cicero et al. 2014; Ito and Hayasi 1991; Dempsey et al. 1999) have the same order of 
magnitude of the grain size. In the case of metals, simple relations between grain size and the critical distance have also been found. In Wilshaw et al (1968), $L$ and $D$ are equal, whereas Yokobori and Konosu (1977) obtained $L=1.2 D$ for the same material subjected to different heat treatments, and then, presenting different grain sizes.

To conclude, the TCD may be considered as an extension of LEFM. Therefore, it shares some of the advantages of LEFM: it can be used to predict brittle failures that happen from different micromechanisms. On the other hand, the TCD also has some of the limitations of LEFM: basically, it is an elastic approach, although its application to the analysis of ductile fracture in metals has provided good results (Susmel and Taylor 2008).

\section{PROPOSED FAILURE CRITERION}

The Griffith's criterion is modified here using a criterion for fracture initiation that considers the critical distance based on the PM. Therefore, the proposed criterion shares most of the simplifying assumptions assumed when applying Griffith's criterion:

- A randomly oriented flaw is considered;

- The problem is simplified to two dimensions and the influence of the intermediate stress is neglected;

- Fracture initiation is identified with "failure" of the rock;

- Fracture propagation is not assessed;

- Crack closure is not considered; 
- Dry static conditions are assumed.

The conceptual model by Griffith (Figure 1) is slightly modified because now there is no need for an elliptical cavity and, to simplify the stress field around the defect, a sharp crack is considered, which is more damaging for the strength of the material than an elliptical or circular defect. In any case, the results for fracture initiation of a sharp crack and a very flat elliptical cavity are the same because notch effects are not visible for notch radii considerably smaller than the critical distance (Taylor 2007).

Maugis (1992) presents a detailed analysis of the stresses and displacements around cracks and elliptical cavities. The common approximate solution for the tangential or circumferential stress in the neighbourhood of the crack tip is:

$$
\sigma_{\theta}=\sqrt{\frac{a}{2 r}} \cos \frac{\theta}{2}\left(\sigma_{y} \cos ^{2} \frac{\theta}{2}-\frac{3}{2} \tau_{x y} \sin \theta\right)+2 \tau_{x y} \sin ^{2} \theta+f(\sqrt{r / a})
$$

This relationship is written as a function of the normal and shear stresses on the crack plane ( $\sigma_{y}$ and $\left.\tau_{x y}\right)$. Please, note that $\sigma_{y}$ and $\tau_{x y}$ are far-field stresses. This approximation is known as the Williams series expansion, and the first term was given by Williams (1957). Here, for the sake of simplicity, only the two first terms will be used. The second term does not depend on $r$, and is usually called the constant term or the $T$ stress. Some authors have discussed improved accuracy including that of the third term (Ayatollahi and Akbardoost 2013) or using an exact solution (Maugis 1992). Eq. (14) may be expressed using stress intensity factors (SIF)

$$
\sigma_{\theta}=\frac{1}{\sqrt{2 \pi r}} \cos \frac{\theta}{2}\left(K_{I} \cos ^{2} \frac{\theta}{2}-\frac{3}{2} K_{I I} \sin \theta\right)+T \sin ^{2} \theta+f(\sqrt{r / a})
$$


or principal stresses

$$
\begin{aligned}
& \sigma_{\theta}=\sqrt{\frac{a}{2 r}} \cos ^{3} \frac{\theta}{2}\left(\sigma_{1} \sin ^{2} \beta+\sigma_{3} \cos ^{2} \beta\right)- \\
& -\frac{3}{2} \sqrt{\frac{a}{2 r}}\left(\sigma_{1}-\sigma_{3}\right) \sin 2 \beta \sin \frac{\theta}{2} \cos ^{2} \frac{\theta}{2}+\left(\sigma_{1}-\sigma_{3}\right) \sin 2 \beta \sin ^{2} \theta+f(\sqrt{r / a})
\end{aligned}
$$

The maximum tangential or hoop stress at the crack tip (Figure 4) and the fracture initiation angle, $\theta_{0}$, is given when

$$
\frac{\partial \sigma_{\theta}}{\partial \theta}=0
$$

So, differentiating Eq. (14)

$$
\cos \frac{\theta_{0}}{2}\left[\sigma_{y} \sin \theta_{0}+\tau_{x y}\left(3 \cos \theta_{0}-1\right)-\frac{32}{3} \tau_{x y} \sqrt{\frac{2 r}{a}} \sin \frac{\theta_{0}}{2} \cos \theta_{0}\right]=0
$$

As shown by Maugis (1992), $\tau_{r \theta}$ is not exactly zero in this direction, and consequently, at a distance $r$ from the crack boundary $\sigma \theta$ is no longer a principal stress as it is at the crack boundary. The stress trajectory starting from the crack tip turns rapidly, and its tangent at a distance $r / a$ is not exactly directed towards the crack tip. However, Eq. (18) is a fair approximation to evaluate $\theta_{0}$.

Application of the PM (Eq. 11) to Eq. (14) gives

$$
\sigma_{0}=\sqrt{\frac{a}{L}} \cos \frac{\theta_{0}}{2}\left(\sigma_{y} \cos ^{2} \frac{\theta_{0}}{2}-\frac{3}{2} \tau_{x y} \sin \theta_{0}\right)+2 \tau_{x y} \sin ^{2} \theta_{0}
$$

where $\theta_{0}$ is implicitly given by Eq. (18) at $r=L / 2$ (Figure 4). 
Rearranging terms in Eq. (19), the proposed failure criteria may be expressed as

$$
\tau_{x y}=\frac{\sigma_{0}-\sigma_{y} \sqrt{\frac{a}{L}} \cos ^{3} \frac{\theta_{0}}{2}}{2 \sin ^{2} \theta_{0}-\frac{3}{2} \sqrt{\frac{a}{L}} \sin \theta_{0} \cos \frac{\theta_{0}}{2}}
$$

Following Griffith's approach, the critical tensile strength, $\sigma_{0}$, may be expressed in terms of the tensile strength, $\sigma_{t}$, applying Eq. (18) and (19) to that case ( $\sigma_{y}=\sigma_{t}$ and $\left.\tau_{x y}=0\right)$, the direction is $\theta_{0}=0$ and

$$
\sigma_{0}=\sqrt{\frac{a}{L}} \sigma_{t}
$$

Note that tensile strengths must be negative as compressions are considered positive throughout the paper. Combining Eq. (20) and (21), the resulting equation is

$$
\tau_{x y}=\frac{\sigma_{t}-\sigma_{y} \cos ^{3} \frac{\theta_{0}}{2}}{2 \sqrt{\frac{L}{a}} \sin ^{2} \theta_{0}-\frac{3}{2} \sin \theta_{0} \cos \frac{\theta_{0}}{2}}
$$

The proposed failure criterion (Eq. 18 and 20 or 22) is compared with the Griffith's criterion (Eq. 6) in Figure 7 in a Mohr's diagram. Similar comparison may be done using the triaxial stress space (Figure 8). The proposed failure criterion using principal stresses may be obtained from Eq. (16). Some relevant features of the proposed criterion are:

- The failure envelope depends on the crack length and the critical distance $(a / L)$.

- The shape of the failure envelope varies with $a / L$ from a near straight line to a near parabolic curve (Figure 7).

- The slope of the failure envelope in the triaxial stress space is proportional to the 
strength ratio $\left(\sigma_{c} / \sigma_{t}\right)$.

- The uniaxial compressive and tensile strengths (Eq. 21) decrease with $a / L$ (Figure 9).

- The strength ratio varies with $a / L$ from less than 3 up to more than 50 (Figure 10).

- The proposed criterion depends on microstructural properties, namely $\sigma_{0}$ and $a / L$, which are difficult to measure, but the failure criterion may also be obtained from $\sigma_{t}$ and $\sigma_{c}$.

- Similar to Griffith's criterion, the proposed model is developed under important simplifying assumptions. However, introducing the critical distance notably improves the predictive capabilities of the failure criterion. It also accounts, at least indirectly, for some microstructural rock features, such as grain size and porosity.

\section{COMPARISON AND DISCUSSION}

\subsection{Input parameters}

The input parameters of the proposed criterion (Eq. 18 and 20) are $\sigma_{0}$ and $a / L$. Based on the TCD, the critical distance, $L$, may be calibrated using any of the following approaches:

- Perform several fracture toughness tests with different notch radii and get the value of the critical distance that gives the best fitting of the results (e.g. Cicero et al. 2014). 
- Perform two fracture toughness tests with two notch radii and get the stress fields around the defect tip (using either analytical solutions or numerical methods). The intersection between these two stress fields corresponds to half the critical distance and the inherent strength (see Figure 3).

Once the value of the critical distance is obtained, the inherent strength, $\sigma_{0}$, may be obtained from Eq. (9) using the material fracture toughness, $K_{I C}$. Lastly, to get the $a / L$ ratio, it is necessary to estimate the length of the initial or pre-existing cracks $(2 a)$, which requires the microstructural analysis of the rock sample.

Alternatively, $\sigma_{0}$ and $a / L$ may be correlated with $\sigma_{c}$ and $\sigma_{t}$. The mathematical relationships are complex and, therefore, for the sake of simplicity they may be graphically obtained using Figures 9 and 10. For example, $a / L$ may be obtained from the $\sigma_{c} / \sigma_{t}$ ratio using Figure 10 or the following approximate expression

$$
\frac{a}{L}=\frac{49}{\sigma_{c} / \sigma_{t}-2.5}
$$

and once $a / L$ is assessed, $\sigma_{0}$ is obtained using Eq. (21) or Figure 9.

In the future, empirical correlations of the critical distance with the type of rock and the grain size may be developed.

\subsection{Brazilian test}

Direct tensile tests are difficult to perform, and they are usually engaged with premature failure due to gripping end effects. Therefore, the tensile strength is usually 
obtained from indirect tests, such as the Brazilian splitting test. Many of the tensile strengths cited in literature were obtained using this test. In this test, failure occurs by tension along the vertical axis, aligned with the opposite line loads, $W$. Using the theory of elasticity, the stresses along this vertical diameter are (e.g. Jaeger et al. 2007):

$$
\sigma_{x}=\frac{-W}{\pi R} \quad ; \quad \sigma_{y}=\frac{W\left(3 R^{2}+y^{2}\right)}{\pi R\left(R^{2}-y^{2}\right)}
$$

where $R$ is the radius of the Brazilian disk, and $y$ is the vertical axis centred in the disk. At the centre of the disk $(y=0)$, the two stresses are the major and minor principal stresses and equal to

$$
\sigma_{3}=\sigma_{x}=\frac{-W}{\pi R} \quad ; \quad \sigma_{1}=\sigma_{y}=\frac{3 W}{\pi R} \Rightarrow \sigma_{1}=-3 \sigma_{3}
$$

So, the results of a Brazilian test in principal stress space are not aligned with the horizontal axis $\left(\sigma_{l}=0\right)$, as pointed out, for example, by Johnston (1985). Eq. (24) may be used as an approximation.

\subsection{Failure envelope}

The proposed failure criterion is here compared with published laboratory measurements. It should be clarified that there are many published data, but here the study limits to high-quality tests and well-documented rocks. Furthermore, the proposed criterion is based on brittle failure, so only tension or low confinement pressures are considered. For intermediate and high confinement stresses, shear failure and ductile behaviour influences rock strength.

Westerly granite is one of the most investigated rocks, for example, Brace (1964) 
presented extension and compression triaxial tests performed on dog-bone-shaped cylindrical specimens. Later, Hopkins (1986) performed similar extension triaxial tests at several temperatures and dry/wet conditions. Only dry specimens at room temperature are considered. Haimson and Chang (2000) tested Westerly granite under true triaxial conditions; only the provided data for conventional compression triaxial tests $\left(\sigma_{2}=\sigma_{3}\right)$ are used. Using these data, the parameters of the proposed criterion $\left(\sigma_{0}\right.$ and $a / L$ ) were varied to give the best fit (Figure 11a). Similar results would be obtained using uniaxial compressive and tensile strengths $\left(\sigma_{c}\right.$ and $\left.\sigma_{t}\right)$. For brittle failure $\left(\sigma_{3}<50\right.$ $\mathrm{MPa}$ ), the best fit of the proposed criterion provides a squared Pearson's correlation coefficient of $\mathrm{r}^{2}=0.972$, showing a good agreement with experimental data for low compressive confining stresses. For tensile stresses, the laboratory measurements present some scatter because of the difficulties associated with this type of test.

Lac du Bonnet granite is another well documented rock (e.g. Carter et al. 1991). It is a strong, very brittle rock, and consequently, the best fit value of $a / L$ is very low, namely 3.7 (Figure 11b). The proposed criterion fits well $\left(r^{2}=0.998\right)$ the measurements for low confinement pressures $\left(\sigma_{3}<15 \mathrm{MPa}\right)$, when tensile stresses dominate rock failure.

Heavily overconsolidated soils also exhibit brittle behaviour at low confining pressures. Bishop and Garga (1969) performed compression and extension triaxial tests on London clay. The best fit of their experimental results provides a value of $a / L=14.5$ (Figure 11c). The $a / L$ parameter is highest in clays and weak clayey rocks, which is related with the grain texture as discussed in the following. 
Figure 12 shows the best fits of the experimental data by Carter et al. (1991) on Lac du Bonnet granite using the proposed analytical criterion for brittle failure and using the Hoek-Brown empirical criterion. For the proposed criterion, the best fit was done considering only brittle failure $\left(\sigma_{3}<15 \mathrm{MPa}\right)$, while the Hoek-Brown criterion allows to consider shear failure at higher confining stresses. However, the Hoek-Brown criterion underestimates tensile strengths as discussed, for example, by Cai (2010). The fitting of the experimental results in Figure 12 with the Mohr-Coulomb shear criterion depends on the confining stress range considered; similar results to the proposed criterion would be obtained if only brittle failure points are considered.

In summary, the proposed failure criterion gives a reasonable estimation of laboratory measurements for tensile fracture, i.e. below the brittle-ductile transition, which is also called the spalling limit (around $\sigma_{1} / \sigma_{3}=10$ ). So, the criterion may be applied for those situations involving brittle failure, such as intact rock brittle failure, spalling or intact rock bridges or pillars.

\subsection{Crack initiation}

The proposed criterion follows the same approach as the Griffith's criterion and, therefore, it is technically a crack initiation criterion. There are few data on crack initiation in the triaxial stress space. The experimental data on Lac du Bonnet granite by Nicksiar and Martin (2013) are here used to validate the proposed theoretical criterion (Figure 13). The unconfined compressive strength reported by Nicksiar and Martin (2013) $\left(\sigma_{c}=220 \mathrm{MPa}\right)$ agrees well with that of Carter et al. (1991). The differences in tension are likely to be caused by the scatter of the experimental data because in tension, 
crack initiation is quickly followed by unstable crack propagation and failure (e.g. Cai 2010).

The best fit parameters of the proposed criterion for the peak strength values used in Figure $11 \mathrm{~b}$, namely $\sigma_{0}=-29 \mathrm{MPa}$ and $a / L=3.7$, are also considered in Figure 13 . For the crack initiation values, the proposed criterion was adjusted assuming that the inherent tensile strength does not change $(\sigma 0=-29 \mathrm{MPa})$, and the value of $a / L$ was varied to give the best fit $(a / L=7)$. The best fits of the proposed criterion match reasonably well the crack initiation and peak strength experimental values for low confining stresses $\left(\sigma_{3}<\right.$ $15 \mathrm{MPa}$ ). Squared Pearson's correlation coefficient is lower for crack initiation values ( $\mathrm{r}^{2}=0.962$ for crack initiation and $\mathrm{r}^{2}=0.998$ for peak strength), but that is caused by the slightly larger scatter of the experimental data for crack initiation. Using best fit values of the model parameters or the uniaxial compressive and tensile peak strengths or crack initiation values, the proposed criterion is able to match experimental data for both peak strength and crack initiation. However, if the model parameters $\left(\sigma_{0}\right.$ and $\left.a / L\right)$ are experimentally measured as presented in Section 5.1, the proposed criterion would give an estimation of the crack initiation values only.

\subsection{Texture and strength ratio}

The range of strength ratios of the proposed failure criterion $\left(\sigma_{c} / \sigma_{t}=3-50\right)$ covers that usually measured in rocks and overconsolidated soils (e.g. Johnston 1985). The constant $m_{i}$ of the Hoek and Brown (1997) criterion is related to the strength ratio. Its value for different type of rocks is presented in Table 1 (Hoek and Brown 1997). The constant $m_{i}$ and, consequently, the strength ratio, are somehow related to the grain size. Fine 
textures usually correspond to lower values of $m_{i}$ and lower strength ratios. That trend is especially evident for sedimentary clastic rocks. In those rocks, the micromechanical model of Figure 5 seems particularly valid. So, small grain sizes correspond to smaller critical distances, and consequently, higher $a / L$ ratios. Since $a / L$ is inversely proportional to the strength ratio in the proposed criterion, the predicted strength ratios agree with the trend in Table 1 . However, the size of existing cracks, $2 a$, may also vary with grain size (e.g. Wong et al. 1996) and other factors, such as porosity or stressinduced microfracture damage during core drilling (i.e., sample disturbance; Eberhardt et al. 1999).

Using the micromechanical model of Figure 5 and assuming that most cracks are related to grain boundaries, the critical distance would be related to the minimum grain size and the crack length to the maximum grain size, because a lower critical distance and a higher crack length would be prone to fracture at lower stress thresholds. So, the $a / L$ parameter of the proposed model is proportional to the variance of the grain size distribution curve. In this way, the proposed model predicts that the rock strength decreases with $a / L$ (Figure 9), and consequently with the heterogeneity of grain sizes. The compressive strength (Figure 9b) is more severely affected than the tensile strength (Figure 9a). Experimental data after Hatzor et al. (1997) are presented in Table 2, showing the different values of $\sigma_{c}$ of two samples with similar percentage of dolomite and porosity but different grain size distributions. The sample with the more uniform grain size distribution (AD43) provides the higher strength. Similar to the grain size distribution, the aspect ratio of the grains also influences the rock strength (Tandon and Gupta 2013). 
The proposed model shows that the rock strength, particularly in compression (Figure 9), depends not on the grain size but on its heterogeneity, i.e. grain size distribution or $a / L$ ratio. Nicksiar and Martin (2014) have also reached this conclusion using numerical models. Their results may be correlated with those predicted by the proposed model (Figure 14). For the purpose of comparison, the sorting coefficient is associated with the $a / L$ ratio along the $x$-axis, to demonstrate the general trend that strength decreases with the grain size heterogeneity.

$a / L$ ratio is difficult to estimate but the crack length $(2 a)$ may be several times the grain size (Hopkins 1986), which is related to the critical distance. The maximum and the average grain sizes of Westerly granite are 0.75 and $0.5 \mathrm{~mm}$, respectively (Brace 1964). Its fracture toughness is around $K_{I C}=1.4 \mathrm{MPa} \cdot \mathrm{m}^{1 / 2}$ (Nasseri et al. 2009). Using the fitted values in Figure 11a of $\sigma_{0}=-40 \mathrm{MPa}$ and $a / L=5$, the critical distance (Eq. 9) and the crack length may be estimated $(2 L=0.78 \mathrm{~mm}$ and $2 a=3.9 \mathrm{~mm})$. Although crack length is difficult to measure, some illustrative images (Figure 15) are provided, for example, by Chen (2008). Similar analysis may be done for Lac du Bonnet granite, whose fracture toughness is $K_{I C}=2.45 \mathrm{MPa} \cdot \mathrm{m}^{1 / 2}$ ( $\mathrm{Li}$ and Lajtai 1998). Using the fitted values in Figure $11 \mathrm{~b}\left(\sigma_{0}=-29 \mathrm{MPa}\right.$ and $\left.a / L=3.7\right)$, the critical distance and the crack length are obtained, $2 L=4.5 \mathrm{~mm}$ and $2 a=16.8 \mathrm{~mm}$, which are in the range of the rock grain size, namely 0.5 $20 \mathrm{~mm}$ (Carter et al. 1991).

\subsection{Porosity}

As reported by many authors (e.g. Tugrul and Zarif 1999), rock strength decreases 
with its porosity. This effect seems obvious and may be considered in the proposed model equating pore size to crack length. Rocks with higher porosity are expected to have longer cracks. The experimental data on arenites for different porosities by Vernik et al. (1993) are fitted with the proposed criterion assuming different crack lengths (Figure 16). Although a detailed comparison is not possible because of the lack of data for tensile stresses, the proposed criterion captures well the decrease of strength with increasing porosity.

\subsection{Sample size and rock weathering}

The influence of sample size on rock strength could be explained using the Griffith's criterion based on the probability of having a crack critically oriented. With the proposed criterion, that can be improved using the length of the critically oriented crack. As the sample diameter increases, the probability of having a longer crack increases, and consequently, $a / L$ increases. That effect is shown in Figure 17 for an Australian coal (Medhurst and Brown 1998). As there are few laboratory data, the proposed fitting by Medhurst and Brown (1998) using the Hoek-Brown (1997) criterion is also shown, as well as an estimation of rock mass strength. The proposed criterion has been fitted varying just $a / L$. A slightly better fitting would be achieved if $\sigma_{0}$ were also changed. Rocks are not perfectly homogeneous, so $\sigma_{0}$ varies, and the probability of having a weaker zone in a bigger specimen is also higher. Ultimately, that value is affected by rock weathering for rock mass.

A set of well-documented Brazilian and triaxial tests in a weak mudstone from Melbourne are provided by Johnston and Chiu (1984). Rock strength decreases with the 
moisture content, as rock weathering increases (Figure 18). Rock weathering is expected to decrease the internal tensile strength, $\sigma 0$, and increase crack length, $2 a$. The fitting of the proposed criterion captures those trends (Figure 18).

\section{CONCLUSIONS}

A new criterion for brittle failure has been developed introducing the critical distance in the Griffith's model of a randomly oriented crack under a biaxial stress state. The proposed criterion is analytical and based on intrinsic properties, such as the inherent tensile strength, $\sigma_{0}$, and the half-length of the crack to the critical distance ratio, $a / L$. These parameters are difficult to measure but they may be correlated with the uniaxial compressive and tensile strengths, $\sigma_{c}$ and $\sigma_{t}$.The proposed criterion accounts for the influence of the crack length ("size effect") and is able to reproduce the common range of strength ratios for rocks and heavily overconsolidated soils $\left(\sigma_{c} / \sigma_{t}=3-50\right)$.

For the sake of simplicity, the proposed failure criterion ignores several processes, such as crack propagation, crack closure, interaction between cracks and influence of the intermediate principal stress. However, a reasonable agreement with laboratory measurements reported in literature is found for tensile and low confining stresses. Furthermore, the model is able to reproduce, by means of its parameters $\sigma_{0}$ and $a / L$, the influence of several microstructural rock properties, such as texture and porosity. It also reproduces the influence of sample size and rock weathering. 


\section{ACKNOWLEDGEMENTS}

The work presented was initiated during a research project on "Structural integrity assessments of notch-type defects", for the Spanish Ministry of Science and Innovation (Ref.: MAT2010-15721).

\section{REFERENCES}

Aliha MRM, Ayatollahi MR, Akbardoost J (2012) Typical upper bound-lower bound mixed mode fracture resistance envelopes for rock material. Rock Mech Rock Eng 45:65-74

Aliha MRM, Ayatollahi MR, Smith DJ, Pavier MJ (2010) Geometry and size effects on fracture trajectory in a limestone rock under mixed mode loading, Eng Fract Mech 77:2200-2210

Anderson TL (2004) Fracture mechanics: fundamentals and applications. 3rd edn. CRC Press, Florida

Ayatollahi MR, Akbardoost J (2013) Size effects in mode II brittle fracture of rocks. Eng Fract Mech 112-113: $165-180$

Bao Y, Jin Z (1993) Size effects and mean strength criterion for ceramics. Fatigue Fract Eng Materials Struct 16:829-835

Baud P, Wong T-f, Zhu W (2014) Effects of porosity and crack density on the compressive strength of rocks. Int J Rock Mech Min Sci 67:202-211

Bažant ZP (2002) Concrete fracture models: testing and practice. Eng Fract Mech 69(2):165-205

Bieniawski ZT (1967) Mechanism of brittle fracture of rock. Part II - Experimental studies. Int J Rock Mech Min Sci 4(4):407-423

Bishop AW, Garga VK (1969) Drained Tension Tests on London Clay. Geotechnique 19(2):309-313

Bobet A (2000) The initiation of secondary cracks in compression. Eng Fract Mech 66:187-219

Bobet A, Einstein HH (1998) Fracture coalescence in rock-type materials under uniaxial and biaxial 
compression. Int J Rock Mech Min Sci 35(7):863-888

Brace WF (1961) Dependence of fracture strength of rocks on grain size. Penn State Univ Min Ind Expt Sta Bull 76:99-103

Brace WF (1964) Brittle fracture of rocks. In: Judd WR (ed) State of stress in the Earth's crust. Elsevier, New York, pp 111-174

Cai M (2010) Practical estimates of tensile strength and Hoek-Brown strength parameter $m_{i}$ of brittle rocks. Rock Mech Rock Eng 43:167-184

Carter BJ, Scott Duncan EJ, Lajtai EZ (1991) Fitting strength criteria to intact rock. Geotech Geol Eng 9:73-81

Chang KJ (1981) Further studies of the maximum stress criterion on the angled crack problem. Eng Fract Mech 14:125-142

Chen Y (2008) Observation of microcracks patterns in westerly granite specimens stressed immediately before failure by uniaxial compressive loading. Chinese J Rock Mech Eng 27(12):2240-2248

Cicero S, García T, Castro J, Madrazo V, Andrés D (2014) Analysis of notch effect in the fracture behaviour of granite and limestone: an approach from the theory of critical distances. Eng Geol 177:1-9

Cicero S, Madrazo V, Carrascal I.A (2012) Analysis of notch effect in PMMA by using the Theory of Critical Distances. Eng Fract Mech 86:56-72

Cicero S, Madrazo V, García T, Cuervo J, Ruiz E (2013) On the notch effect in load bearing capacity, apparent fracture toughness and fracture mechanisms of polymer PMMA, aluminium alloy Al7075T651 and structural steels S275JR and S355J2. Eng Fail Anal 29:108-121

Cotterell B (1965) On brittle failure paths. Int J Fract Mech 1:96-103

Cotterell B, Rice JR (1980) Slightly curved or kinked cracks. Int J Fract 16:155-169

Dempsey JP, Adamson RM, Mulmule SV (1999) Scale effect on the in-situ tensile strength and failure of ice. Part II: First-year sea ice at Resolute, N.W.T. Int J Fract 95:347-366

Dyskin AV (1997) Crack growth criteria incorporating non-singular stresses: Size effect in apparent 
fracture toughness. Int J Fract 83:191-206

Eberhardt E., Stead D, Stimpson B (1999) Effects of sample disturbance on the stress-induced microfracturing characte-ristics of brittle rock. Can Geotech J 36:239-250.

Elices M, Planas J, Guinea GV (2000) Fracture mechanics applied to concrete. In: Fuentes et al. (eds) European Structural Integrity Society. Elsevier, Vol 26, pp 183-210

Erdogan F, Sih GC (1963) On the crack extension in plates under plane loading and transverse shear. ASME, J Basic Eng 85(4):519-527

Griffith AA (1921) The phenomena of rupture and flow in solids. Phil Trans Royal Soc London, Series A 221:163-198

Griffith AA (1924)Theory of rupture. In: Bienzano CB, Burgers JM (eds) Proc. 1st International Congress on Applied Mechanics, Delft, pp 55-63

Haimson B, Chang C (2000) A new true triaxial cell for testing mechanical properties of rock, and its use to determine rock strength and deformability of Westerly granite. Int J Rock Mech Min Sci 37:285296

Hatzor YH, Zur A, Mimran Y (1997) Microstructure effects on microcracking and brittle failure of dolomites. Tectonophysics 281:141-161

Hoek E (1965) Rock fracture under static stress conditions. PhD Thesis, University of Cape Town

Hoek E (1968) Brittle failure of rock. In: Stagg KG, Zienkiewicz OC (eds) Rock Mechanics in Engineering Practice. John Wiley and Sons, pp 99-124

Hoek E, Brown ET (1980) Empirical Strength Criterion for Rock Masses. J Geotech Eng Div, ASCE 106(GT9):1013-1135

Hoek E, Brown ET (1997) Practical estimates of rock mass strength. Int J Rock Mech Min Sci 34:11651186

Hopkins TW (1986) Microfracturing in Westerly granite experimentally extended wet and dry at temperatures to $800^{\circ} \mathrm{C}$ and pressures to $200 \mathrm{MPa}$. MSc Thesis, Texas A\&M University

Inglis CE (1913) Stresses in a plate due to the presence of cracks and sharp corners. Trans Inst Naval 
Architects 55(Part I): 219-230

Ingraffea AR, Heuzé FE (1980) Finite element models for rock fracture mechanics. Int J Num Anal Methods Geomech 4:25-43

Ito T (2008) Effect of pore pressure gradient on fracture initiation in fluid saturated porous media: Rock. Eng Fract Mech 75:1753-1762

Ito T, Hayasi K (1991) Physical background to the breakdown pressure in hydraulic fracturing tectonic stress measurements. Int J Rock Mech Min Sci 28:285-293

Jaeger JC (1967) Failure of rocks under tensile conditions. Int J Rock Mech Min Sci 4(2):219-227

Jaeger JC, Cook NGW, Zimmerman RW (2007) Fundamentals of Rock Mechanics. 4th edn. WileyBlackwell

Johnston IW (1985) Strength of Intact Geomechanical Materials. J Geotech Eng, ASCE 111(6):730-749

Johnston IW, Chiu HK (1984) Strength of Weathered Melbourne Mudstone. J Geotech Eng, ASCE 110(7):875-898

Karihaloo BL, Carpinteri A, Elices M (1993) Fracture mechanics of cement mortar and plain concrete. Adv Cem Based Mater 1 (2):92-105

Kemeny JM (1991) A model for non-linear rock deformation under compression due to sub-critical crack growth. Int J Rock Mech Min Sci 28(6):459-467

Lajtai EZ (1972) Effect of tensile stress gradient on brittle fracture initiation. Int J Rock Mech Min Sci $9(5): 569-578$

Li S, Lajtai EZ (1998) Modeling the stress-strain diagram for brittle rock loaded in compression. Mech Materials 30:243-251

Madrazo V, Cicero S, Carrascal IA (2012) On the point method and the line method notch effect predictions in A17075-T651. Eng Fract Mech 2012; 79:363-379

Maugis D (1992) Stresses and displacements around cracks and elliptic cavities - exact solutions. Eng Fract Mech 43:217-255

Medhurst TP, Brown ET (1998) A study of the mechanical behaviour of coal for pillar design. Int J Rock 
Mech Min Sci 35(8):1087-1105

Nasseri MHB, Tatone BSA, Grasselli G, Young RP (2009) Fracture Toughness and Fracture Roughness Interrelationship in Thermally treated Westerly Granite. Pure Applied Geophysics 166:801-822

Neuber H (1958) Theory of notch stresses: principles for exact calculation of strength with reference to structural form and material. Springer Verlag, Berlin

Nicksiar M, Martin CD (2013) Crack initiation stress in low porosity crystalline and sedimentary rocks. Eng Geol 154:64-76

Nicksiar M, Martin CD (2014) Factors affecting crack initiation in low porosity crystalline rocks. Rock Mech Rock Eng 47:1165-1181

Paterson MS, Wong T-f(2005) Experimental rock deformation - The brittle field. Springer Verlag, Berlin

Peterson RE (1959) Notch sensitivity. In: Sines G, Waisman JL (eds) Metal fatigue. McGraw Hill, New York, pp 293-306

Pluvinage G (1998) Fatigue and fracture emanating from notch; the use of the notch stress intensity factor. Nuclear Eng Design 185:173-184

Pugno N, Ruoff R (2004) Quantized fracture mechanics. Phil Magaz 84:2829-2845

Shen B, Stephansson O (1993) Numerical-analysis of mixed mode-I and mode-II fracture propagation. Int J Rock Mech Min Sci 30:861-867

Smith DJ, Ayatollahi MR, Pavier MJ (2001) The role of T-stress in brittle fracture for linear elastic materials under mixed mode loading. Fatigue Fract Eng Materials Struct 24:137-150

Sneddon IN (1946) The distribution of stress in the neighbourhood of a crack in an elastic solid. Proc Royal Soc, Series A 187(1009):229-260

Susmel L, Taylor D (2008) On the use of the Theory of Critical Distances to predict filures in ductile metallic materials containing different geometrical features. Eng Fract Mech 75:4410-4421

Susmel L, Taylor D (2010) An elasto-plastic reformulation of the Theory of Critical Distances to estimate lifetime of notched components failing in the low/medium-cycle fatigue regime. J Eng Materials Tech, Trans ASME 132:0210021-0210028 
Tandon RS, Gupta V (2013) The control of mineral constituents and textural characteristics on the petrophysical \& mechanical (PM) properties of different rocks of the Himalaya. Eng Geol 153:125143

Taylor D (2007) The Theory of Critical Distances: A New Perspective in Fracture Mechanics. Elsevier Sci

Taylor D, Wang G (2000) The validation of some methods of notch fatigue analysis. Fatigue Fract Eng Materials Struct 23:387-394

Tugrul A, Zarif IH (1999) Correlation of mineralogical and textural characteristics with engineering properties of selected granitic rocks from Turkey. Eng Geol 51(4): 303-317

Usami S, Kimoto H, Takahashi I, Shida S (1986) Strength of ceramic materials containing small flaws. Eng Fract Mech 23:745-761

Vernik L, Bruno M, Bovberg C (1993) Empirical relations between compressive strength and porosity of siliciclastic rocks. Int J Rock Mech Min Sci 30(7):677-680

Williams JG, Ewing PD (1972) Fracture under complex stress - the angled crack problems. Int J Fract $8: 441-446$

Williams ML (1957) On the stress distribution at the base of a stationary crack. J Applied Mech 24(1):109-114

Wilshaw TR, Rau CA, Tetelman AS (1968) A general model to predict the elastic-plastic stress distribution and fracture strength of notched bars in plane strain bending. Eng Fract Mech 1:191-211

Wong RHC, Chau KT, Wang P (1996) Microcracking and grain size effect in Yuen Long marbles. . Int J Rock Mech Min Sci 33(5):479-485

Wu Z, Wong LNY (2012) Frictional crack initiation and propagation analysis using the numerical manifold method. Comput Geotech 39:38-53

Yokobori T, Konosu S (1977) Effects of ferrite grain size, notch acuity and notch length on brittle fracture stress of notched specimens of low carbon steel. Eng Fract Mech 8:397-409

Zhou S, Guo S (2009) Two-parameter criterion for crack growth under compressive loading. Int J Rock Mech Min Sci 46:1389-1393 


\section{TABLE CAPTIONS}

Table 1. Values of the constant $m_{i}$ of the Hoek-Brown criterion (Hoek and Brown 1997).

Table 2. Influence of grain size distribution on $\sigma_{c}$ (Hatzor et al. 1997). 
Table 1. Values of the constant $m_{i}$ of the Hoek-Brown criterion (Hoek and Brown 1997).

\begin{tabular}{|c|c|c|c|c|c|c|}
\hline \multirow{2}{*}{ Rock type } & \multirow{2}{*}{ Class } & \multirow{2}{*}{ Group } & \multicolumn{4}{|c|}{ Texture } \\
\hline & & & Coarse & Medium & Fine & Very fine \\
\hline \multirow{5}{*}{ Sedimentary } & \multirow[t]{2}{*}{ Clastic } & & $\begin{array}{c}\text { Conglomerate } \\
\text { (22) }\end{array}$ & $\begin{array}{c}\text { Sandstone } \\
19\end{array}$ & $\begin{array}{l}\text { Siltstone } \\
9\end{array}$ & $\begin{array}{c}\text { Claystone } \\
4\end{array}$ \\
\hline & & & \multicolumn{4}{|c|}{------- Geywacke (18) -------- } \\
\hline & \multirow{3}{*}{$\begin{array}{l}\text { Non- } \\
\text { clastic }\end{array}$} & Organic & \multicolumn{4}{|c|}{ 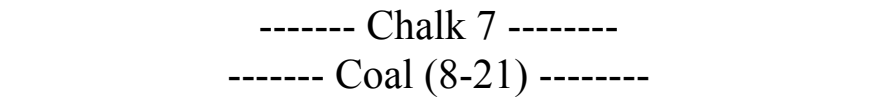 } \\
\hline & & Carbonate & $\begin{array}{l}\text { Breccia } \\
\quad(20)\end{array}$ & $\begin{array}{c}\text { Sparitic } \\
\text { Limestone } \\
(10)\end{array}$ & $\begin{array}{c}\text { Micritic } \\
\text { Limestone } \\
8\end{array}$ & \\
\hline & & Chemical & & $\begin{array}{c}\text { Gypstone } \\
16\end{array}$ & $\begin{array}{c}\text { Anhydrite } \\
13\end{array}$ & \\
\hline \multirow{3}{*}{ Metamorphic } & \multicolumn{2}{|c|}{ Non-foliated } & $\begin{array}{l}\text { Marble } \\
9\end{array}$ & $\begin{array}{l}\text { Hornfels } \\
(19)\end{array}$ & $\begin{array}{c}\text { Quartzite } \\
(24)\end{array}$ & \\
\hline & \multicolumn{2}{|c|}{ Slightlty foliated } & $\begin{array}{l}\text { Migmatite } \\
\text { (30) }\end{array}$ & $\begin{array}{l}\text { Amphibolite } \\
25-31\end{array}$ & $\begin{array}{l}\text { Mylonites } \\
\text { (6) }\end{array}$ & \\
\hline & \multicolumn{2}{|c|}{ Foliated* } & $\begin{array}{c}\text { Gneiss } \\
33\end{array}$ & $\begin{array}{c}\text { Schists } \\
4-8\end{array}$ & $\begin{array}{l}\text { Phyllites } \\
\text { (10) }\end{array}$ & $\begin{array}{l}\text { Slate } \\
9\end{array}$ \\
\hline \multirow{3}{*}{ Igneous } & \multicolumn{2}{|c|}{ Light } & $\begin{array}{c}\text { Granite } \\
33 \\
\text { Granidiorite } \\
(30) \\
\text { Diorite } \\
(28) \\
\end{array}$ & & $\begin{array}{c}\text { Rhyolite } \\
\text { (16) } \\
\text { Dacite } \\
(17) \\
\text { Andesite } \\
19 \\
\end{array}$ & $\begin{array}{l}\text { Obsidian } \\
\text { (19) }\end{array}$ \\
\hline & \multicolumn{2}{|c|}{ Dark } & $\begin{array}{c}\text { Gabbro } \\
27 \\
\text { Norite } \\
22\end{array}$ & $\begin{array}{l}\text { Dolerite } \\
\text { (19) }\end{array}$ & $\begin{array}{c}\text { Basalt } \\
(17)\end{array}$ & \\
\hline & \multicolumn{2}{|c|}{ Extrusive pyroclastic } & $\begin{array}{l}\text { Agglomerate } \\
\text { (20) }\end{array}$ & $\begin{array}{l}\text { Breccia } \\
\text { (18) }\end{array}$ & $\begin{array}{l}\text { Tuff } \\
(15)\end{array}$ & \\
\hline
\end{tabular}

Notes: Values in parenthesis are estimates.

*These values are for intact rock specimens tested normal to bedding or foliation. 
Table 2. Influence of grain size distribution on $\sigma_{c}$ (Hatzor et al. 1997).

\begin{tabular}{ccccccc}
\hline Sample & $\begin{array}{c}\text { Porosity } \\
(\%)\end{array}$ & $\begin{array}{c}\text { Mineralogy } \\
\text { \% dolomite }\end{array}$ & $\begin{array}{c}D_{\max } \\
(\mu \mathrm{m})\end{array}$ & $\begin{array}{c}D_{\text {avg }} \\
(\mu \mathrm{m})\end{array}$ & $D_{\max } / D_{\text {avg }}$ & $\begin{array}{c}\sigma_{c} \\
(\mathrm{MPa})\end{array}$ \\
\hline AD5 & 5.8 & 70 & 450 & 35 & 12.9 & 98 \\
AD43 & 5.4 & 75 & 64.3 & 24.4 & 2.6 & 274 \\
\hline
\end{tabular}

$D_{\max }$ : Maximum grain size ; Davg: Average grain size. 


\section{FIGURE CAPTIONS}

Figure 1. Griffith's conceptual model.

Figure 2. Global and local polar coordinate systems.

Figure 3. Obtaining $L$ and $\sigma_{0}$ parameters.

Figure 4. Application of the point method.

Figure 5. Stress redistribution near the defect tip.

Figure 6. Discontinuous crack growth, on which the TCD (FFM) is based.

Figure 7. Failure criterion in Mohr's diagram.

Figure 8. Failure criterion in principal stress space.

Figure 9. Variation of tensile and compressive strengths.

Figure 10. Compressive/tensile strength ratio.

Figure 11. Application of failure criterion to: (a) Westerly granite; (b) Lac du Bonnet granite; (c) London clay.

Figure 12. Comparison with Hoek-Brown criterion.

Figure 13. Comparison between crack initiation (data after Nicksiar and Martin 2013) and peak strength values (data after Carter et al. 1991) on Lac du Bonnet granite.

Figure 14. Influence of grain size distribution or $a / L$ on uniaxial compression.

Figure 15. Typical microcracks observed in an intact specimen of Westerly granite (Chen 2008): (a) Crossed nicols; (b) Observation by fluorescent method (brightest parts correspond to cracks).

Figure 16. Influence of porosity on rock strength.

Figure 17. Influence of sample size.

Figure 18. Influence of moisture content on mudstone strength. 


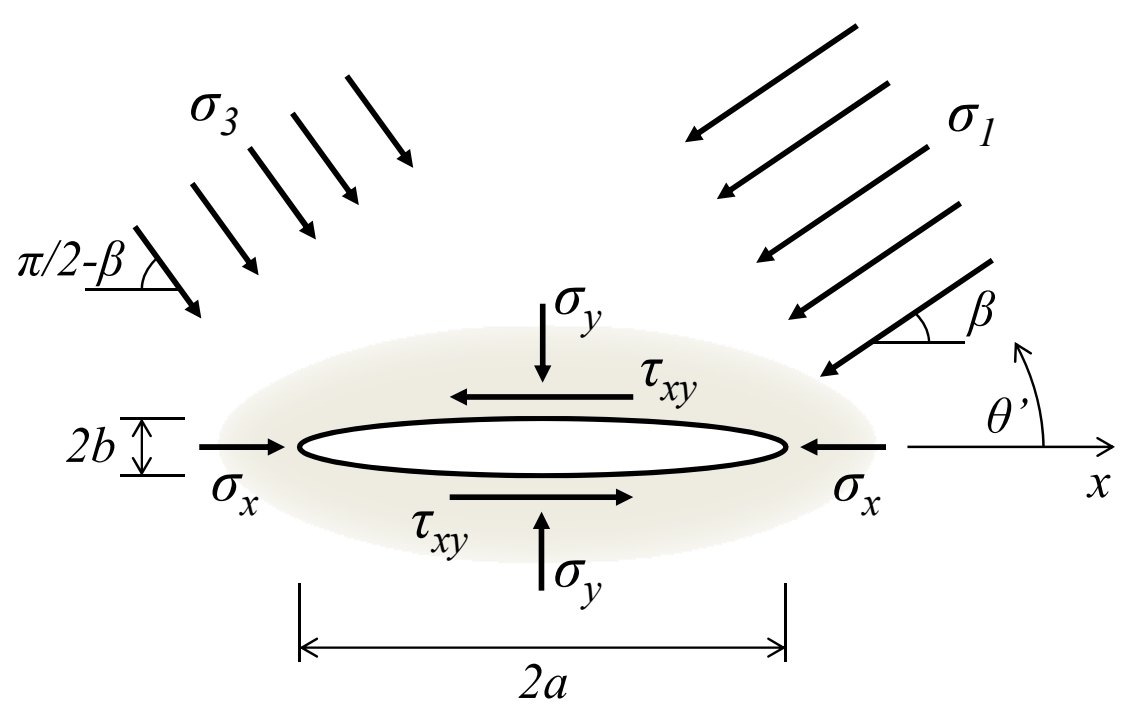

Figure 1. Griffith's conceptual model.

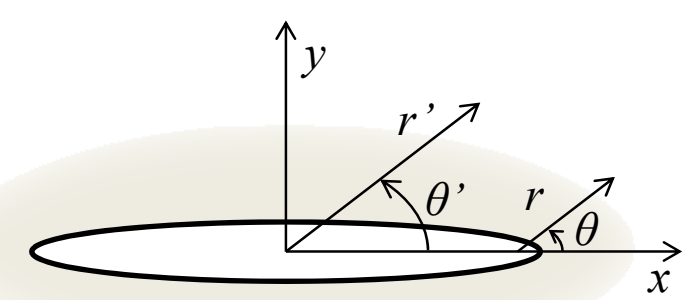

Figure 2. Global and local polar coordinate systems. 


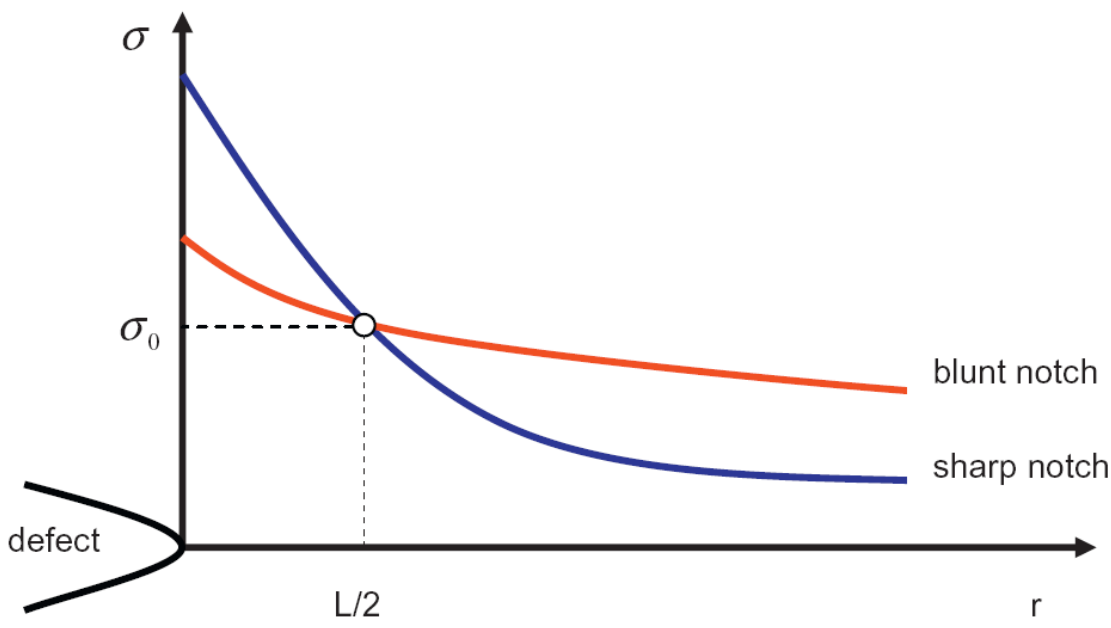

Figure 3. Obtaining $L$ and $\sigma_{0}$ parameters.

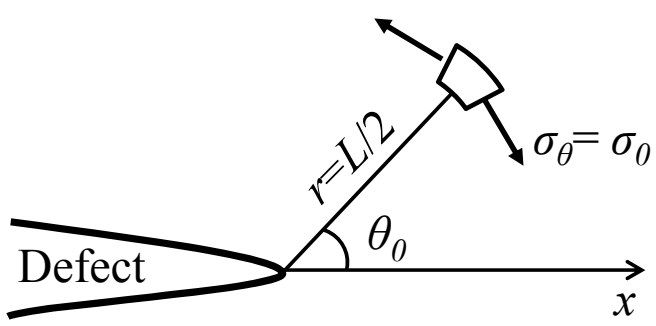

Figure 4. Application of the point method. 


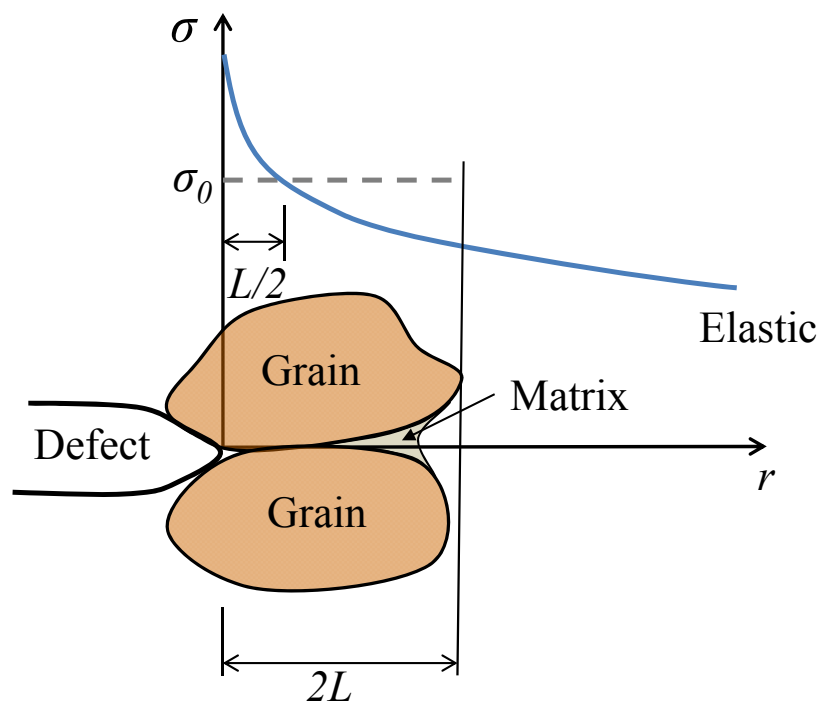

Figure 5. Stress redistribution near the defect tip.

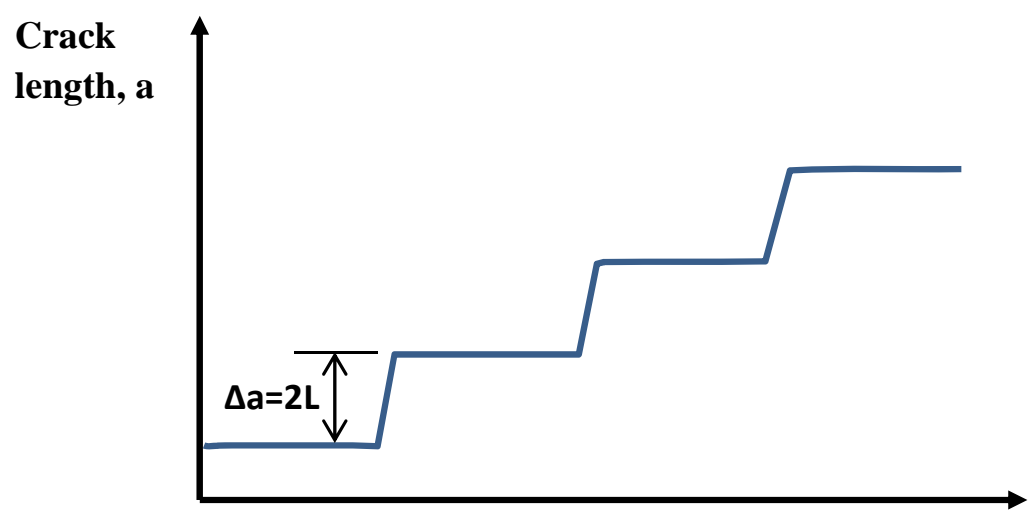

Time, $\mathbf{t}$

Figure 6. Discontinuous crack growth, on which the TCD (FFM) is based. 


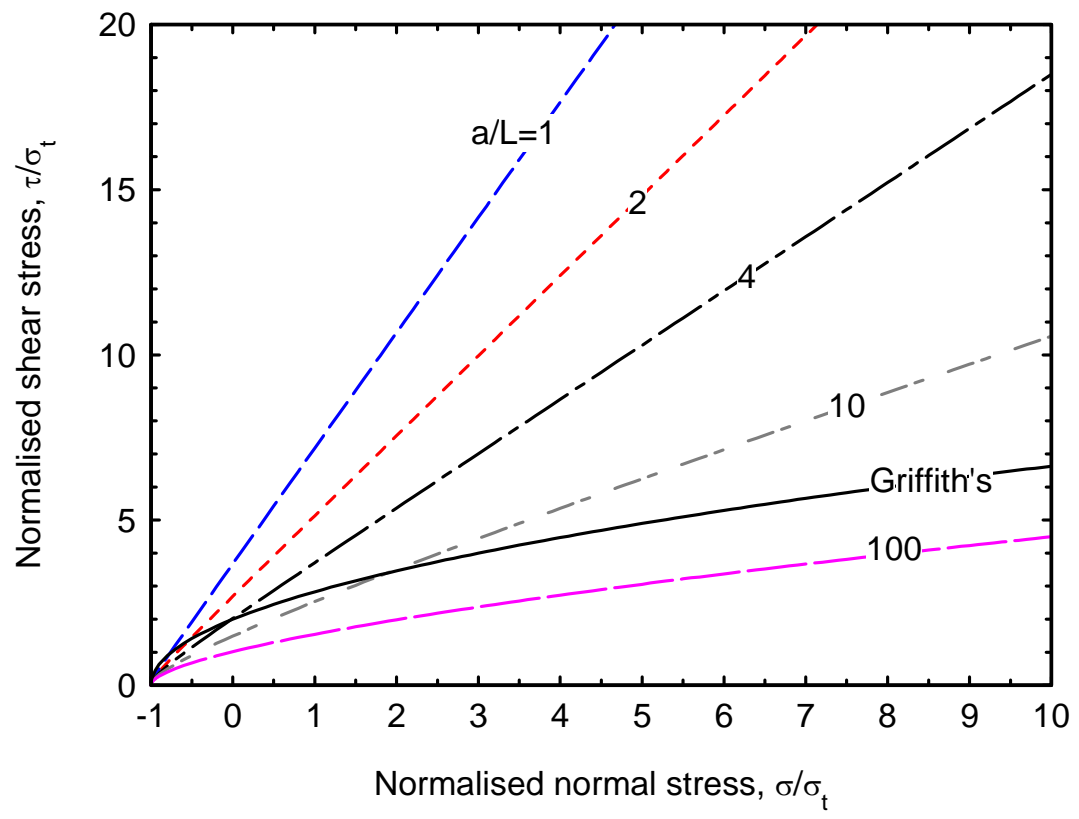

Figure 7. Failure criterion in Mohr's diagram.

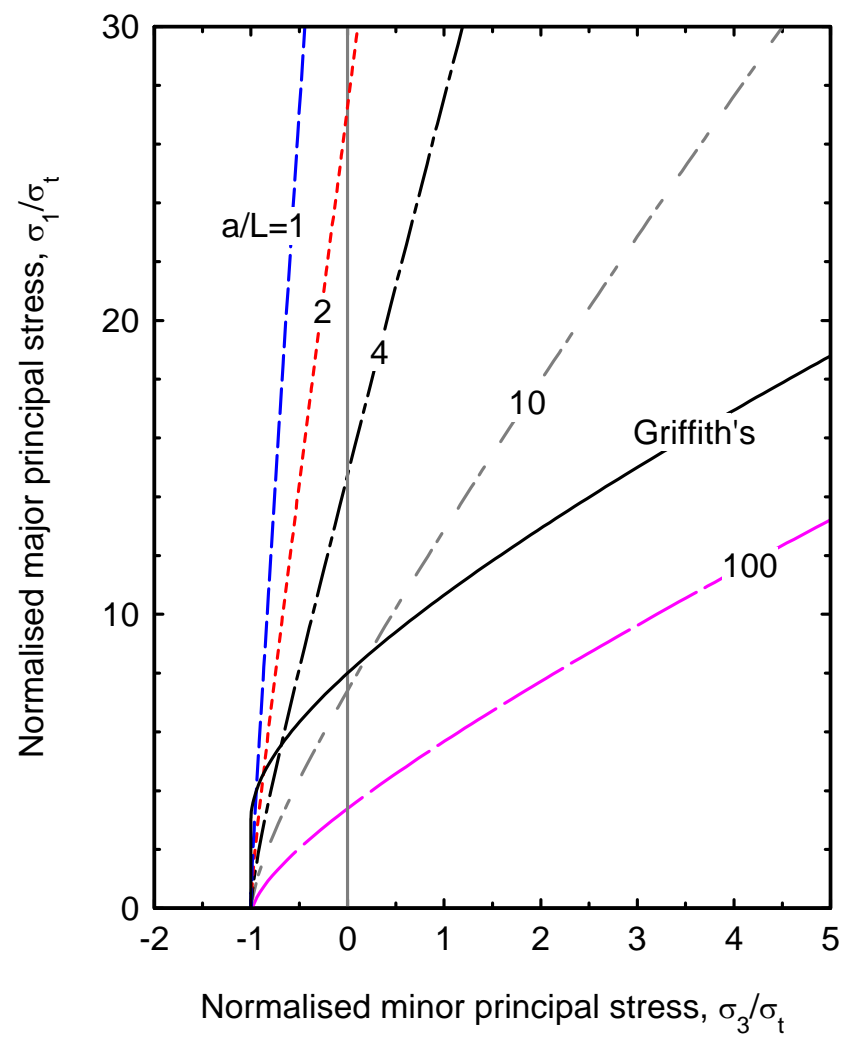

Figure 8. Failure criterion in principal stress space. 


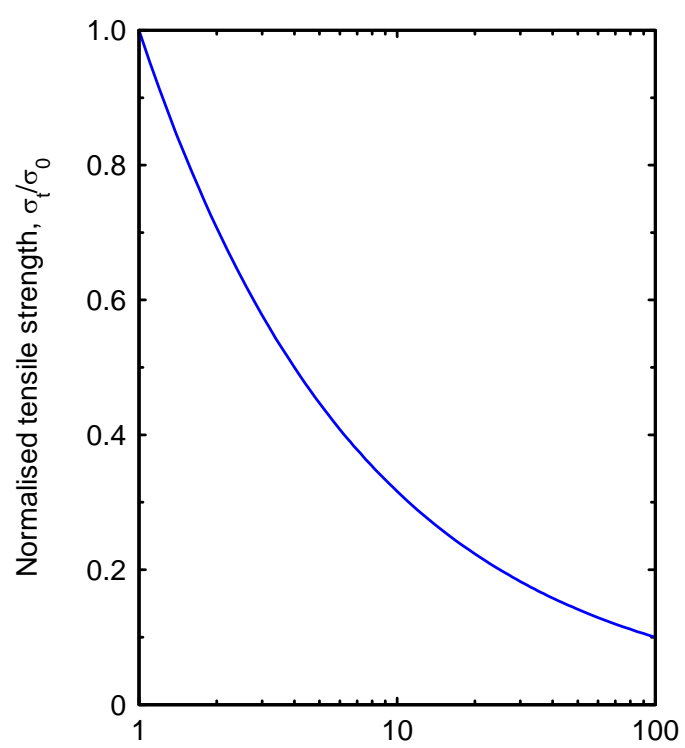

Half-length of the flaw / Critical distance, a/L

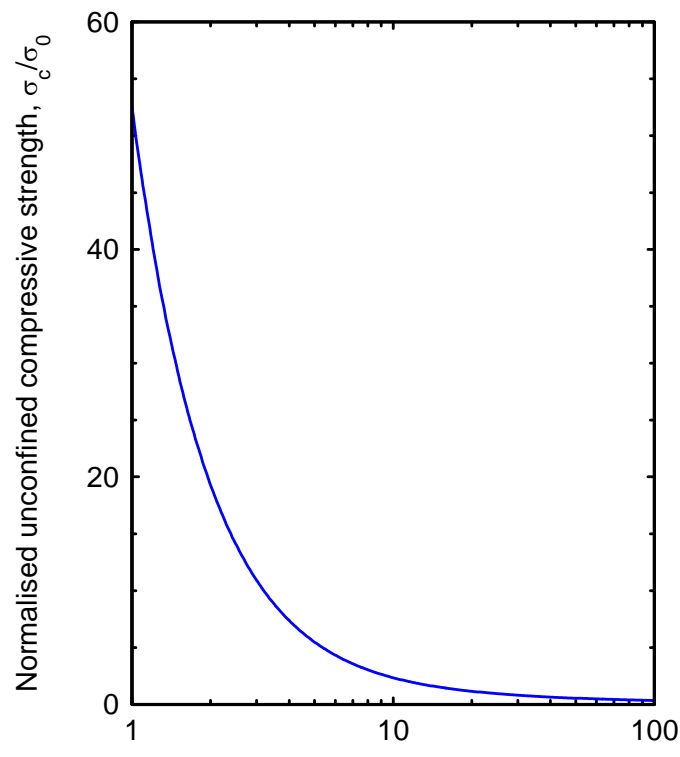

Half-length of the flaw / Critical distance, a/L

Figure 9. Variation of tensile and compressive strengths.

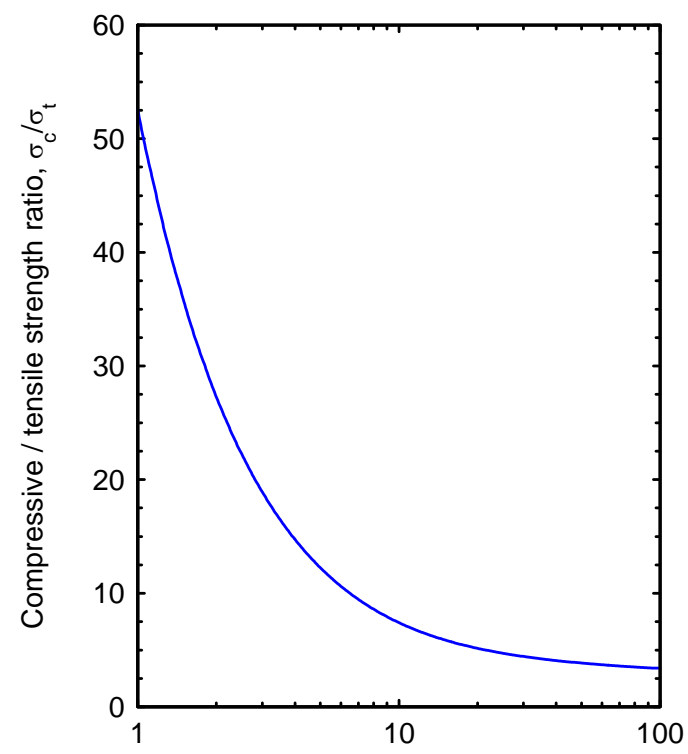

Half-length of the flaw / Critical distance, a/L

Figure 10. Compressive/tensile strength ratio. 

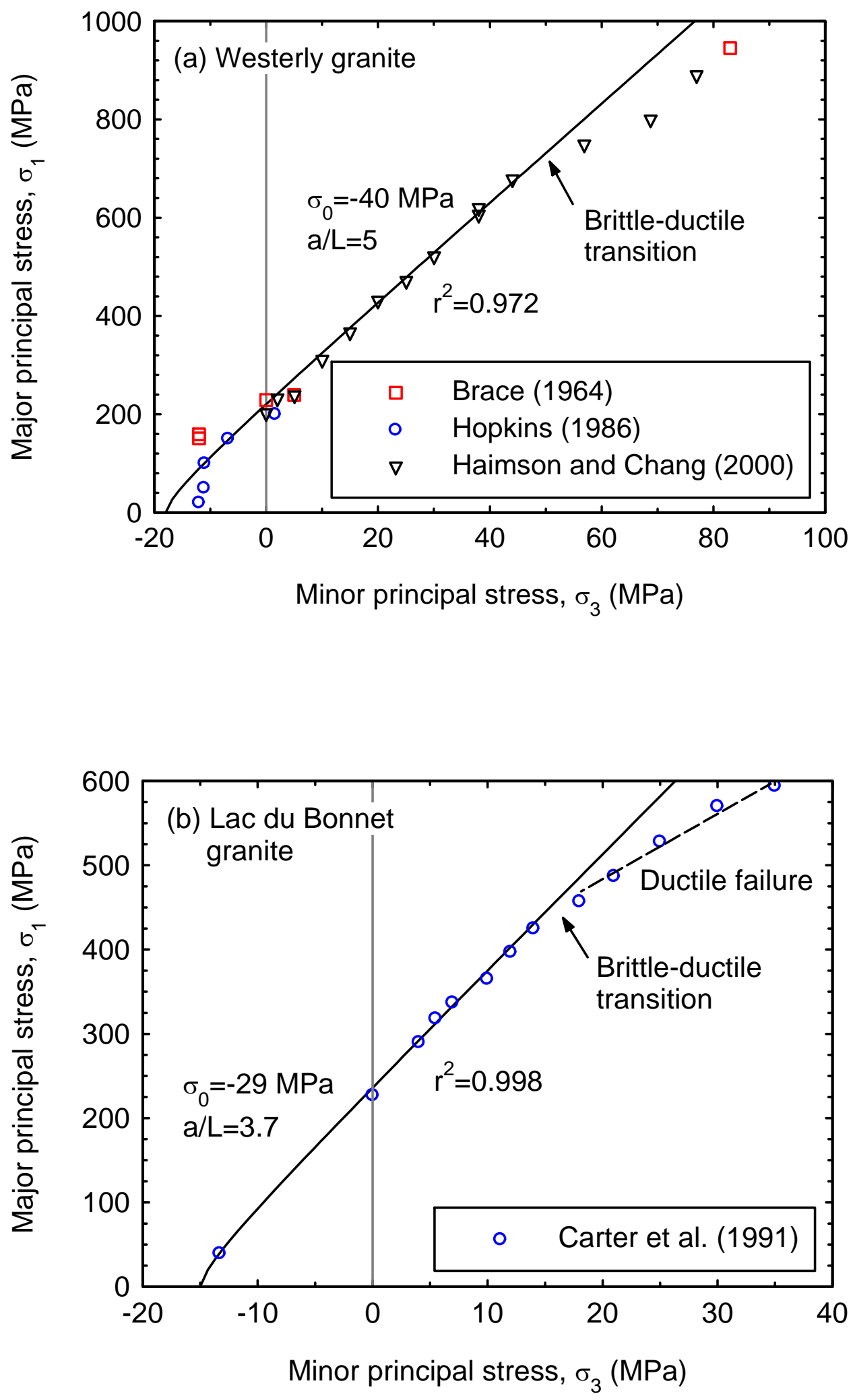


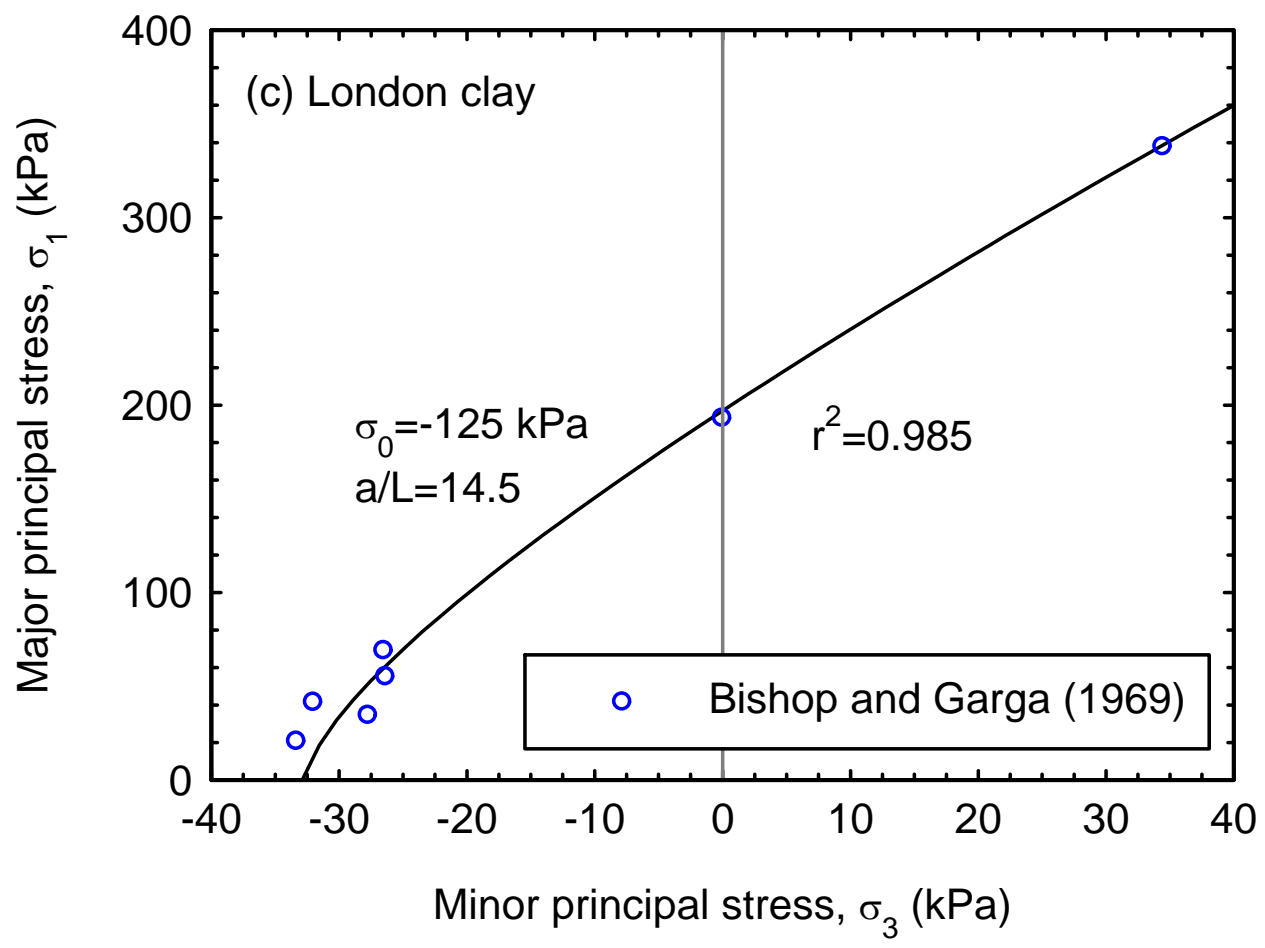

Figure 11. Application of failure criterion to: (a) Westerly granite; (b) Lac du Bonnet granite; (c) London clay.

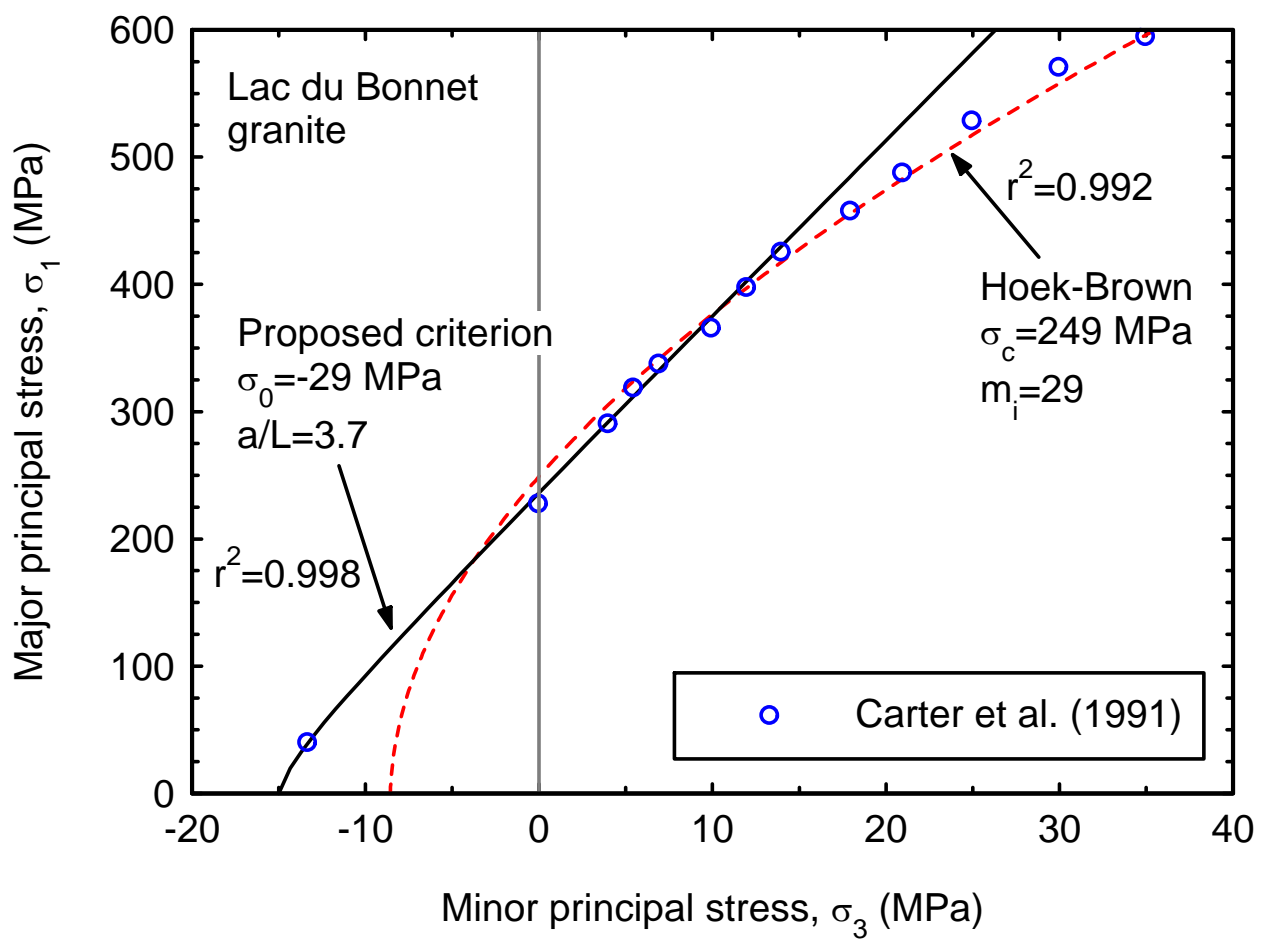

Figure 12. Comparison with Hoek-Brown criterion. 


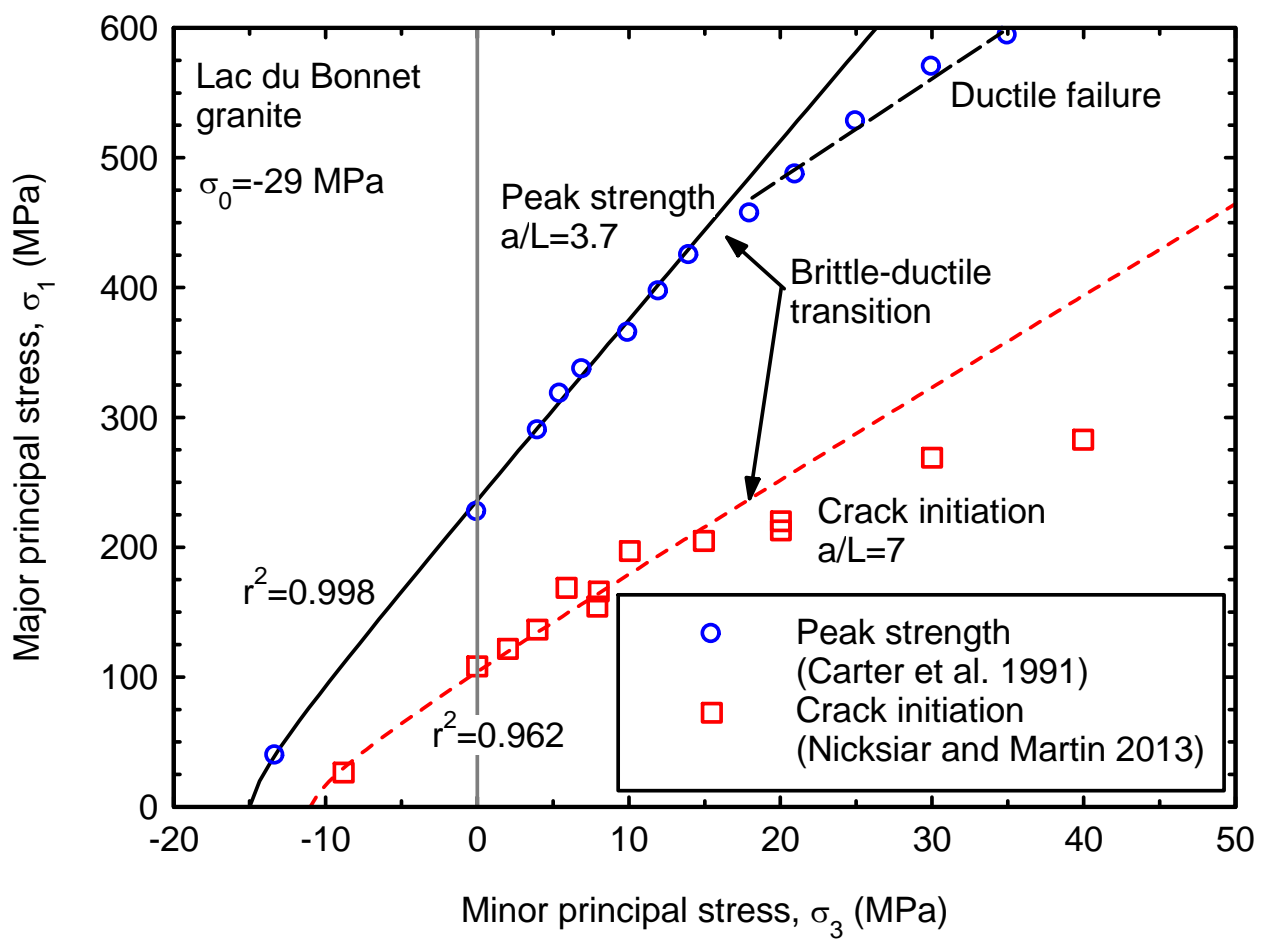

Figure 13. Comparison between crack initiation (data after Nicksiar and Martin 2013) and peak strength values (data after Carter et al. 1991) on Lac du Bonnet granite.

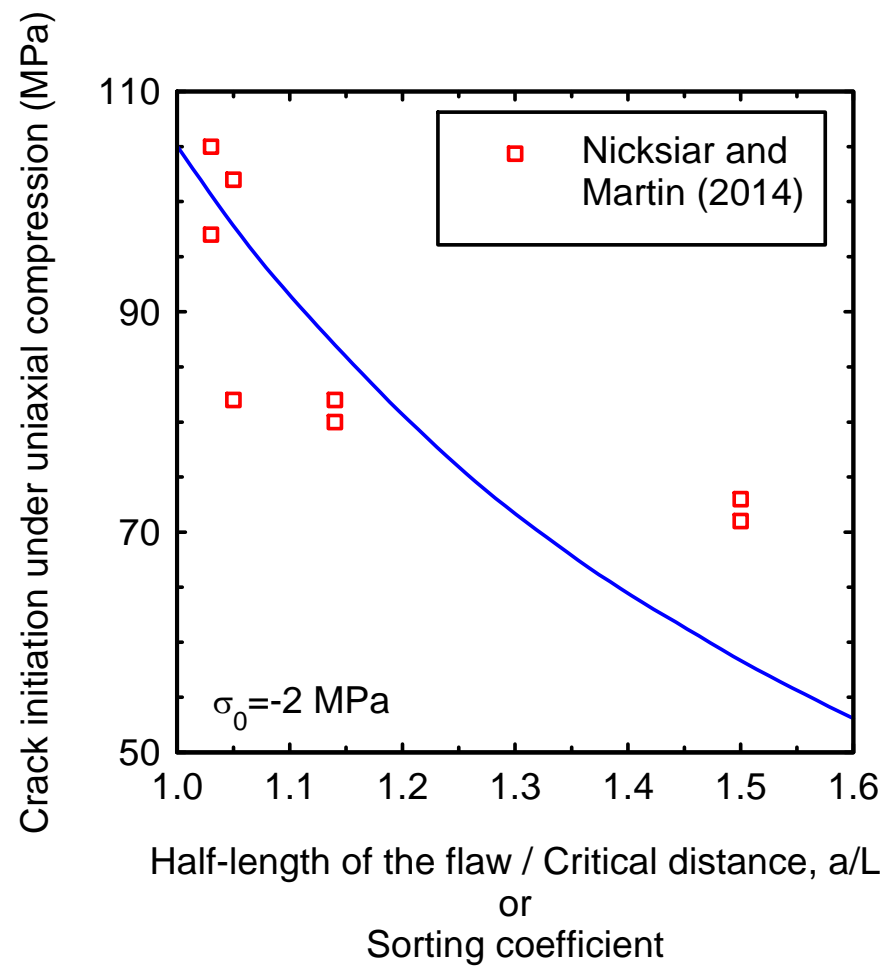

Figure 14. Influence of grain size distribution or $a / L$ on uniaxial compression. 

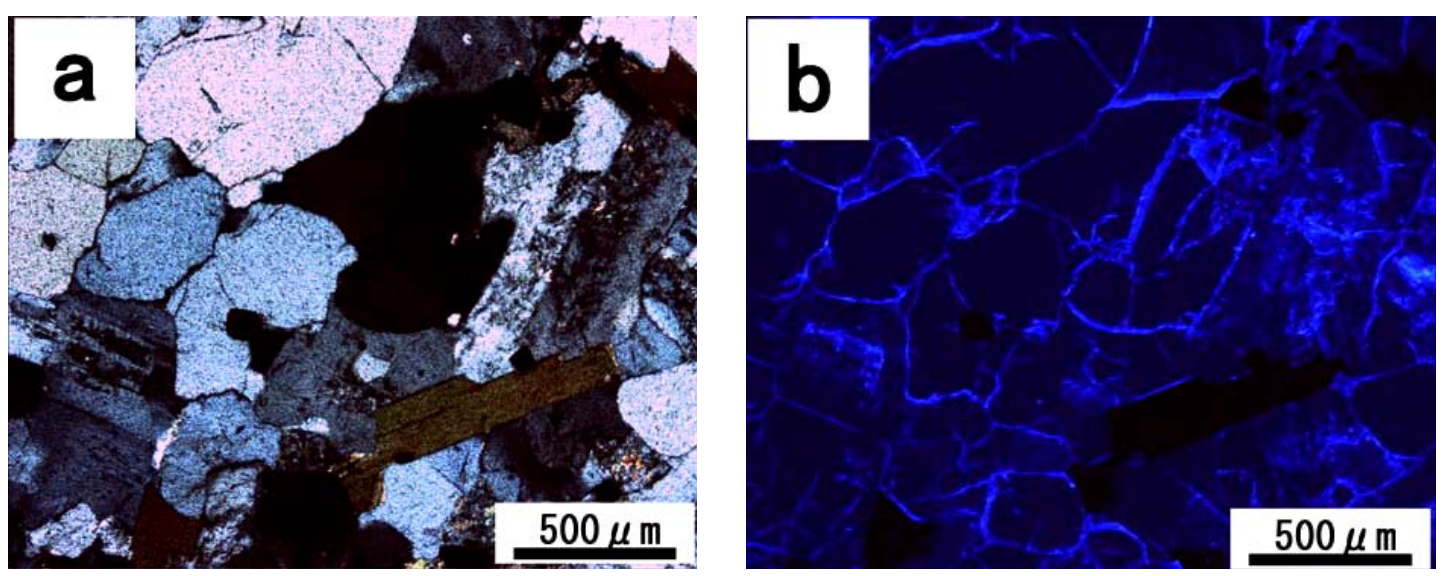

Figure 15. Typical microcracks observed in an intact specimen of Westerly granite

(Chen 2008): (a) Crossed nicols; (b) Observation by fluorescent method (brightest parts correspond to cracks).

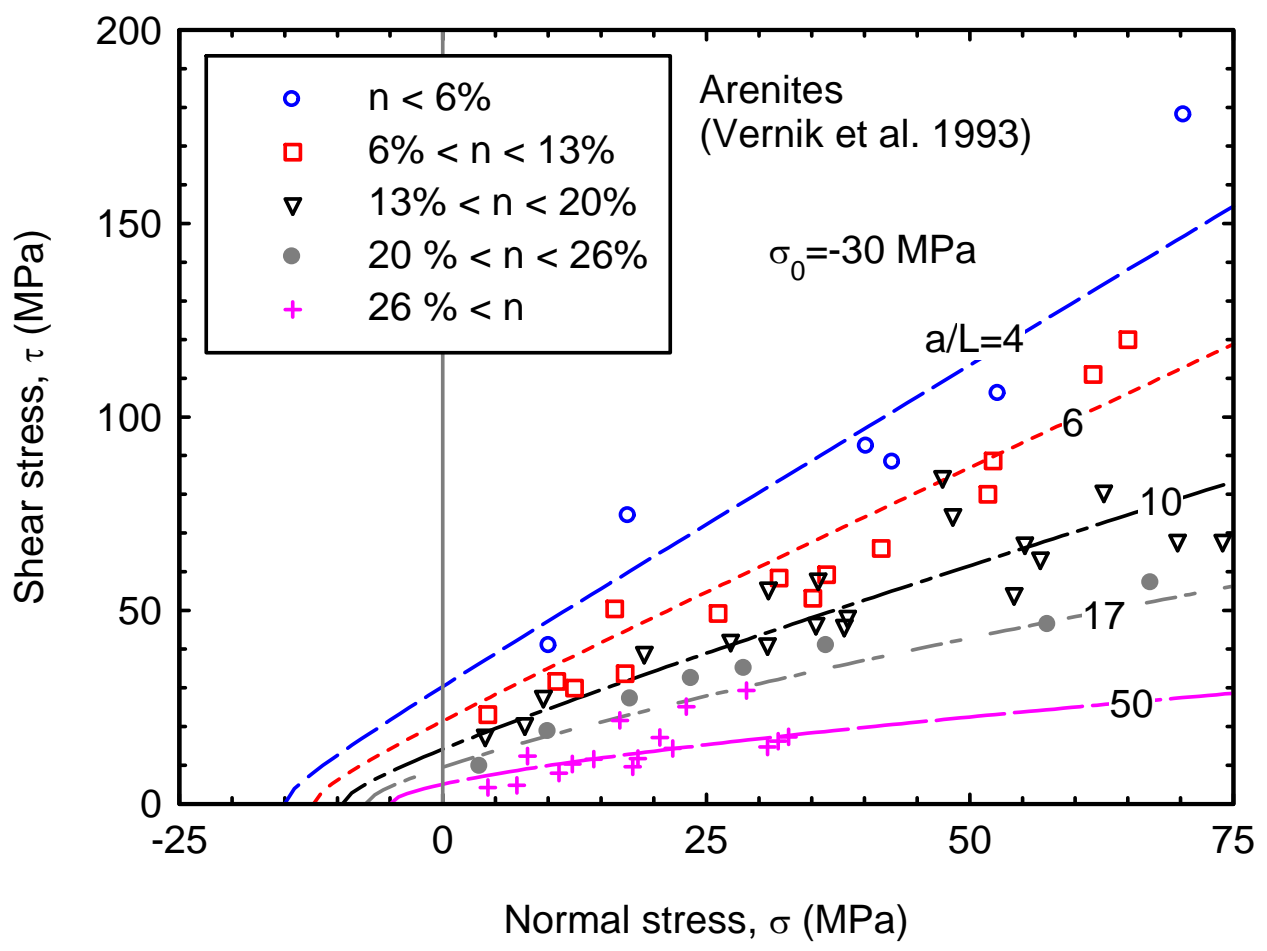

Figure 16. Influence of porosity on rock strength. 


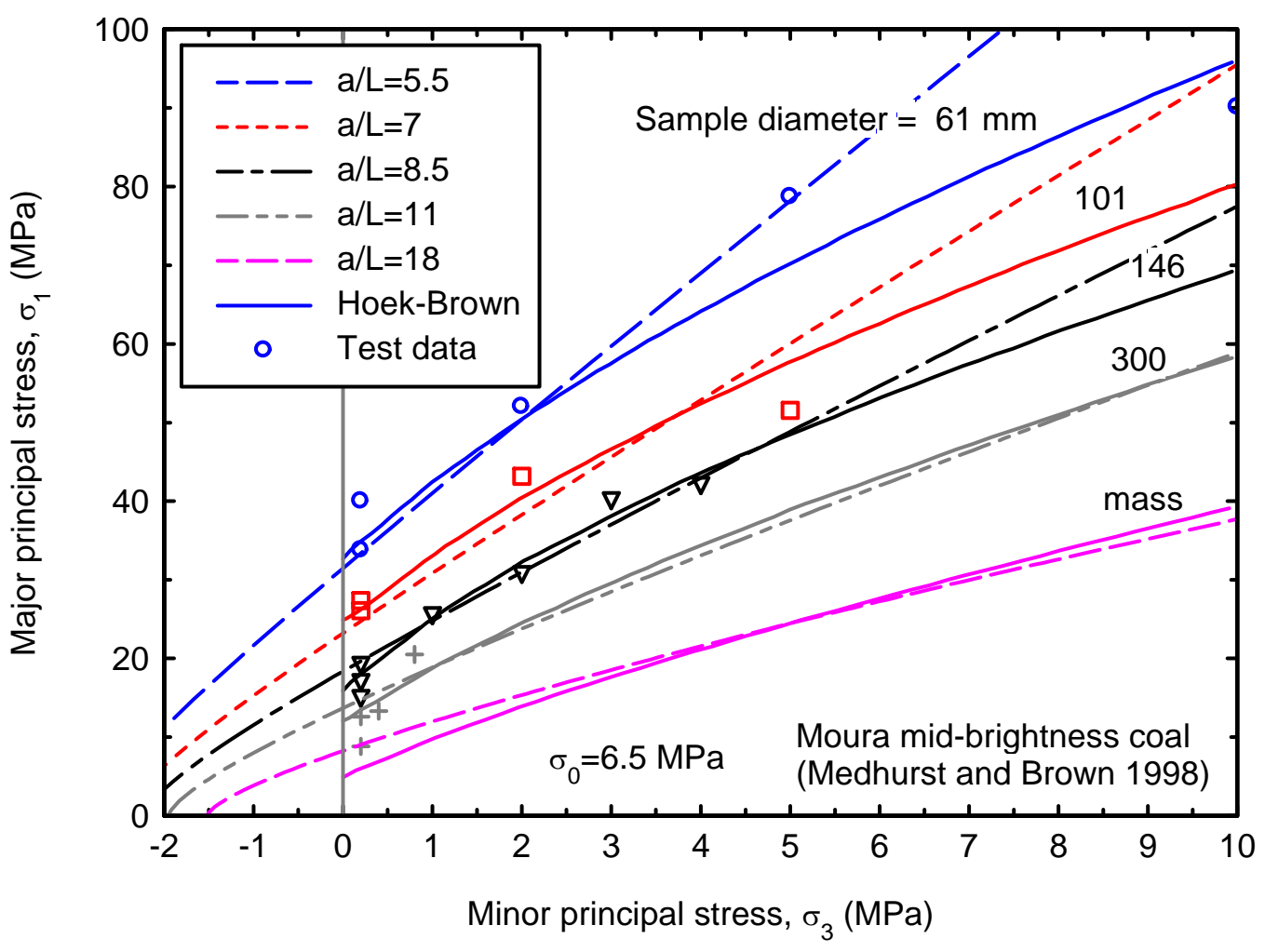

Figure 17. Influence of sample size.

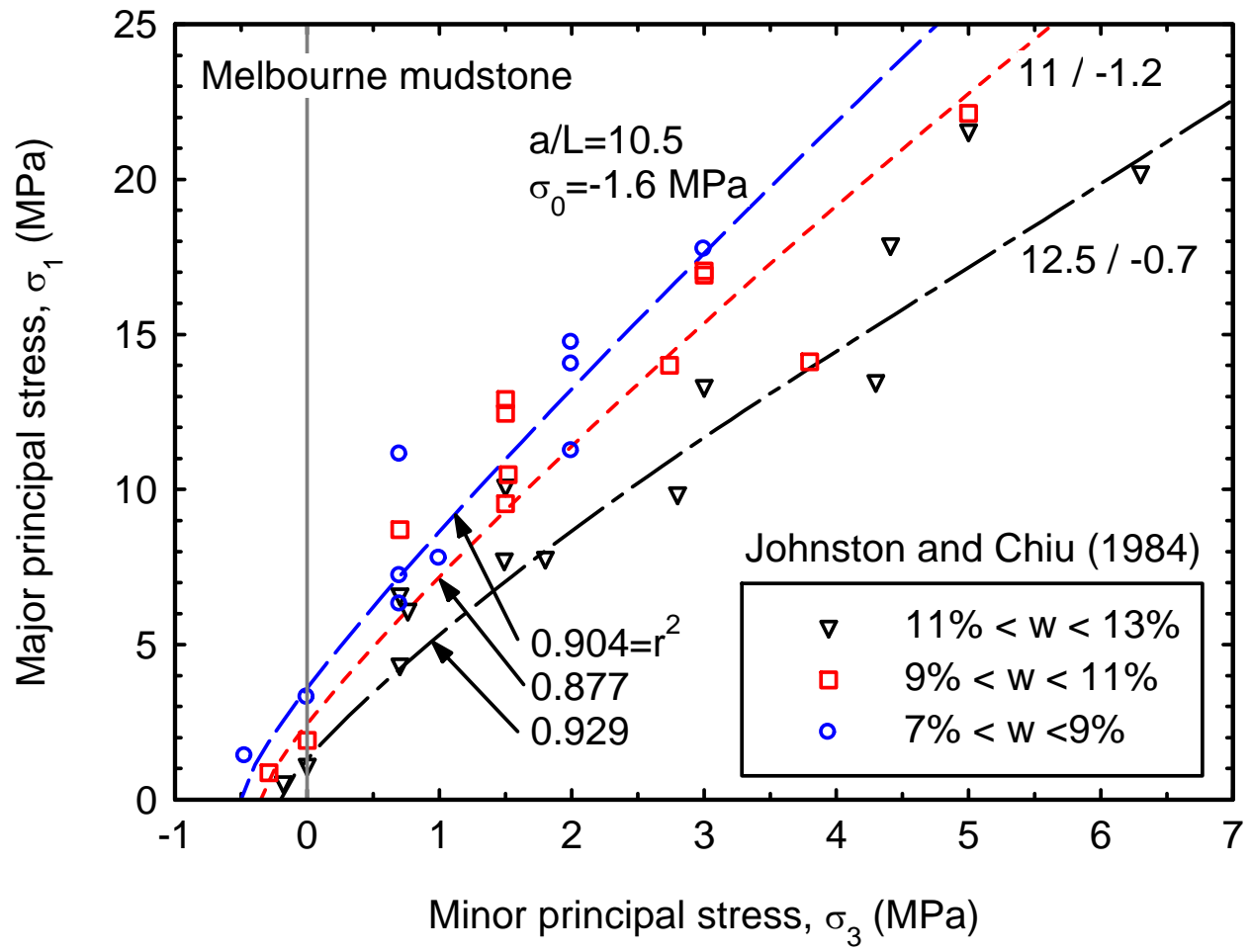

Figure 18. Influence of moisture content on mudstone strength. 